\title{
Selbsthilfeorganisationen und -gruppen in der Verhaltensmedizin: Übersicht und Beschreibung
}

\author{
Manfred Fichter ${ }^{a}, \mathrm{~b} \quad$ Marian Cebulla ${ }^{\mathrm{a}}$ \\ aMedizinisch-Psychosomatische Klinik Roseneck, Prien am Chiemsee \\ bLudwig-Maximilians-Universität, Psychiatrische Klinik und Poliklinik, Forschungsbereich Epidemiologie und Evaluation, München
}

\section{Schlüsselwörter}

Selbsthilfe - Selbsthilfegruppen .

Selbsthilfeorganisationen · Verhaltensmedizin

\section{Zusammenfassung}

Hintergrund: Selbsthilfevereinigungen sind in den letzten Jahren ein fester Bestandteil der Gesundheitsversorgung in der Bundesrepublik Deutschland geworden. Damit ist es an der Zeit für eine Bestandsaufnahme. Wir haben eine bundesweite Befragung von Selbsthilfeorganisationen (SHO) und relevanten Selbsthilfegruppen (SHG) im Bereich der Verhaltensmedizin durchgeführt und möchten die wesentlichen Ergebnisse einem möglichst großen Kreis von Fachleuten und Selbsthilfe-Interessierten zugänglich machen. Methode: Aus verschiedenen Teilbereichen der Verhaltensmedizin wurden 70 SHO und SHG ausgewählt (Allergie und Asthma, angeborene Behinderungen, Angehörige psychisch Kranker, Angststörungen, chronische Schmerzen, Erkrankungen des Bewegungsapparates, gastrointestinale Erkrankungen und Inkontinenz, Ess-Störungen, Hauterkrankungen, Hör- und Sprachbehinderungen, Lebenskrisen, neurologische Erkrankungen und Behinderungen, Persönlichkeitsstörungen und psychische Probleme, Sucht/Abhängigkeit sowie Zwangsstörungen). Den ausgewählten Selbsthilfevereinigungen wurde ein strukturierter Fragebogen zugeschickt, der die Teile (1) Anschrift, (2) Kontaktaufnahme, (3) Zielgruppe, (4) Aufgaben und Ziele, (5) Angebote, (6) Struktur der Einrichtung sowie (7) Anmerkungen erfasste. Ergebnisse: Insgesamt haben $90 \%$ der angeschriebenen Selbsthilfevereinigungen geantwortet. 56 schickten den Fragebogen ausgefüllt zurück, 5 Selbsthilfevereinigungen legten anstelle des Fragebogens umfangreiches Informationsmaterial bei und 30 haben sowohl den Fragebogen ausgefüllt als auch zusätzlich Informationsmaterial beigelegt. Die Darstellung verdeutlicht das umfangreiche Angebot der SHO und SHG sowie ihre Bedeutung für das Gesundheitssystem. Schlussfolgerungen: Mit unserer Darstellung hoffen wir, eine informative Übersicht und Beschreibung der SHO und SHG zur Verfügung zu stellen und somit die bereits bestehende Kooperation zwischen Fachleuten und Selbsthilfevereinigungen weiter zu fördern und zu unterstützen.

\section{Key Words}

Behavioral medicine · Self-help · Self-help groups ·

Self-help organizations

\section{Summary}

Self-help Organizations and Groups in Behavioral

Medicine: Overview and Description

Background: Over the past years self-help organizations have become an essential part of prevention and rehabilitation in German health care. It was the aim of our enquiry to inform experts and interested persons about the most important self-help organizations (SHO) and self-help groups (SHG) of different fields in behavioral medicine. Methods: 70 SHO and SHG of different fields in behavioral medicine were selected dealing with allergy and asthma, congenital disorders, relatives of patients with psychic disorders, anxiety disorders, chronic pain disorders, eating disorders, diseases of the musculoskeletal system, diseases of the gastrointestinal tract and incontinence, skin diseases, hearing and speech disorders, life crises, disorders pertaining to the nervous system, personality disorders and psychic problems, abuse, or obsessive-compulsive disorders. The selected SHO and SHG received a structured questionnaire including questions regarding (1) address, (2) means of contact, (3) group of interest, (4) tasks and aims, (5) provision, (6) structure of organizations, and (7) comments. Results: $90 \%$ of SHO replied, $56 \mathrm{SHO}$ sent back the questionnaire completely answered, 5 institutions sent material of information instead, and 30 included both questionnaire and information material. The data clearly show the extensive support SHO might offer to sufferers. Conclusions: This report provides an informative overview of SHO. It might help to support the already existing cooperation between experts and $\mathrm{SHO}$ in this field.

\begin{tabular}{ll}
\hline KARGER & @ 2001 S. Karger GmbH, Freiburg \\
$\begin{array}{l}\text { Fax +49 7614520714 } \\
\begin{array}{l}\text { E-mail Information@Karger.de } \\
\text { www.karger.com }\end{array}\end{array}$ & Accessible online at: \\
www.karger.com/journals/ver
\end{tabular}

Prof. Dr. med. Dipl.-Psych. Manfred Fichter Medizinisch-Psychosomatische Klinik Roseneck Am Roseneck 6

D-83209 Prien am Chiemsee (Deutschland) Tel. +49 805168 35-10, Fax -32 E-Mail Mfichter@t-online.de 


\section{Hintergrund}

Selbsthilfeorganisationen (SHO) und Selbsthilfegruppen (SHG) sind in den letzten Jahren ein fester Bestandteil der Gesundheitsversorgung in der Bundesrepublik Deutschland (BRD) geworden. Neben der therapeutischen Bedeutung kommt ihnen auch eine alltägliche und politische Bedeutung zu [Moeller, 1996]. 1999 wurde die Zahl der örtlichen SHG auf 70000 bis 100000 geschätzt [Matzat, 1999]. Allein im Raum Hamburg sind etwa 25000 Menschen in über 1400 SHG aktiv [KISS, 1999]. Viele der SHG haben im Lauf der Zeit professionelle Strukturen entwickelt (bundesweite Vereinigungen mit Landesstellen und regionalen Gruppen). Andere arbeiten autonom auf regionaler Ebene und konzentrieren ihre Arbeit auf direkte Unterstützung von Betroffenen durch psychosoziale Gesprächsgruppen.

Die fachliche und öffentliche Anerkennung der SHG war nicht immer gegeben. Bis Ende der 1970er Jahre wurden SHG von professionellen Helfern, Krankenkassen und Politik nicht zur Kenntnis genommen [Matzat, 1999]. Nach Moeller [z.B. 1996] lässt sich die sprunghafte Entwicklung der SHO und SHG in den vergangenen Jahrzehnten in 5 Phasen beschreiben:

1. Die Entstehungszeit (1955-1975). Mitte der 1950er Jahre entstanden die Anonymen Alkoholiker (AA) als eine der ersten SHG in der BRD. Von den AA leiteten sich zahlreiche weitere «anonyme» SHG ab. 1972 wurden die ersten deutschen Anonymen Neurotikergruppen (AN) gegründet [Moeller, 1975]. Ende der 1970er Jahre entstanden die ersten SHG für Essgestörte (Overeaters Anonymous, OA) [Brunner, 1990].

2. Die Zusammenarbeit von SHG und Fachleuten (1975-1981). 1977 wurde das erste Forschungsprojekt über «PsychologischTherapeutische Selbsthilfegruppen» an der psychosomatischen Universitätsklinik in Gießen begonnen [Daum et al., 1984]. Die Ergebnisse riefen bei den Fachleuten sowohl Neugier als auch Widerstand hervor [Matzat, 1999]. Gegen Ende der zweiten Phase wuchs jedoch die Einsicht, dass eine $\mathrm{Zu}$ sammenarbeit für beide Seiten hilfreich wäre.

3. Der Durchbruch (1981-1984). Die dritte Phase brachte die breite Anerkennung der SHG. Die Deutsche Arbeitsgemeinschaft Selbsthilfegruppen (DAG SHG) e.V. wurde 1982 zur Unterstützung und Verbreitung des Selbsthilfegruppen-Ansatzes gegründet. 1984 entstand die Nationale Kontakt- und Informationsstelle zur Anregung und Unterstützung von Selbsthilfegruppen (NAKOS) in Berlin. Auf örtlicher Ebene entstanden zahlreiche Selbsthilfe-Kontaktstellen [Matzat, 1999].

4. Qualität und Unterstützung der SHG seit 1984. In der vierten Phase stand die Verbesserung der Qualität der SHG-Arbeit im Vordergrund. Hier spielen die unterschiedlichen Arten von Selbsthilfe-Zusammenschlüssen eine wichtige Rolle (v.a. SHO und SHG). Sie haben unterschiedliche Aufgaben und gelten als gleichrangig.
5. Die Zukunft einer ganzheitlichen mehrdimensionalen Selbsthilfe. Nach der Differenzierung der Selbsthilfeinitiativen auf allen Gebieten setzte nun ihre Integration ein.

Moeller [1983; 1996] unterscheidet 7 Arten von Selbsthilfevereinigungen. Die wichtigsten sind die Gesprächsselbsthilfegruppen (SHG) und die Selbsthilfeorganisationen (SHO). SHG arbeiten in der Regel auf lokaler Ebene und verfolgen «innere» (v.a. psychotherapeutische) Selbsthilfeziele [Daum et al., 1982]. Die Teilnehmer von SHG treffen sich regelmäßig und versuchen gemeinsam eine Selbstveränderung zu erreichen. Idealtypisch hat die SHG keinen Leiter, sondern lebt von der Verantwortung jedes einzelnen Gruppenmitglieds für sich selbst und das Gruppengeschehen. Weitere Merkmale von SHG sind: Gleichberechtigung, Selbstbetroffenheit, Selbstindikation, Schweigepflicht und kostenlose Teilnahme. Nach Fichter [1976] ist die Rolle der Betroffenen in Selbsthilfevereinigungen durch gemeinsames Interagieren und gemeinsame Bearbeitung der Probleme gekennzeichnet. Gruppendynamische Experimente haben gezeigt, dass die Gemeinschaft als Ganzes fähiger zur Problemlösung bzw. -bearbeitung ist als der einzelne, so ist z.B. die soziale Wahrnehmung und somit die Einsichtsfähigkeit erhöht. Durch das Fehlen des Therapeuten und den Aufforderungscharakter des Settings (Selbsthilfe) werden Autonomie-Tendenzen gefördert [Moeller, 1975]. Es gibt jedoch auch andere SHG - z.B. mit regelmäBiger Anleitung (z.B. jede 10. Sitzung) durch einen Experten. Dafür können auch Kosten entstehen. Eine lokale Gruppe der «Anonymen Alkoholiker» stellt z.B. eine SHG dar.

Ein Beispiel für eine SHO ist die Dachorganisation der einzelnen «Anonymen Alkoholiker». SHO verfolgen primär «äußere» Selbsthilfeziele wie z.B. Informationsvermittlung, Forschungsförderung, Öffentlichkeitsarbeit, Konzeptentwicklung und -verbreitung. SHO sind zentraler organisiert und helfen, einzelne lokale SHG zu koordinieren, mit Informationen zu versorgen und sie anderweitig zu unterstützen. SHO sind in den meisten Fällen als eingetragener Verein organisiert und unterliegen somit dem Vereinsrecht. Durch die Satzung werden Vereinsziele und -aufgaben sowie Rechte und Pflichten von Mitgliedern und Mandatsträgern festgelegt [Mathis, 1999]. Beispiele für SHO sind die Deutsche Tinnitus-Liga (DTL) e.V. und der Deutsche Allergie- und Asthmabund (DAAB) e.V.

Die anderen 5 Arten von Selbsthilfevereinigungen sind: bewusstseinsverändernde SHG (z.B. Frauen- und Männergruppen; Homosexuellen-Gruppen), lebensgestaltende SHG (z.B. Wohngemeinschaften und Landkommunen), arbeitsorientierte SHG (z.B. SHG von Arbeitslosen), lern- bzw. ausbildungsorientierte SHG (z.B. Psychotherapeuten in selbstorganisierter Fortbildung) und Bürgerinitiativen. Gemeinsame Merkmale aller SHG sind Selbstbetroffenheit und das Handeln in eigener Sache [Moeller, 1983; 1996].

In den letzten Jahren entstanden im World Wide Web die ersten interaktiven SHG. Online-SHG realisieren sich v.a. in Selbsthilfe-Mailinglisten, Selbsthilfe-Newsgroups (Diskus- 
sionsforen) und Selbsthilfe-Chats [Döring, 2000]. Mailinglisten sind Diskussionsgruppen, deren Kommunikation über E-Mail realisiert wird. Durch Einschreiben in eine Mailingliste bekommt der Teilnehmer alle E-Mails, die an die Liste geschrieben werden. Im Gegensatz zu einer Newsgroup sind Mailinglisten nicht weltweit einsehbar. Die Daten können nur von angemeldeten Mitgliedern eingesehen werden. Die AA bieten Mailinglisten an, die durch monatlich rotierende Chairpersonen geleitet und moderiert werden. Selbsthilfe-Chats ermöglichen es, mit mehreren Personen in Echtzeit zu kommunizieren. Chat-Foren werden in der Regel von 5-30 Personen besucht.

SHG-Arbeit kann in vielfältiger Weise mit professioneller Hilfe verbunden werden, z.B. als Nachfolgeselbsthilfegruppe nach einer ambulanten oder stationären psychotherapeutischen Behandlung [Moeller, 1982]. Für die Zukunft ist zu wünschen, dass im Sinne der Betroffenen die Zusammenarbeit zwischen professionellen Helfern und Selbsthilfevereinigungen noch weiter vertieft werden kann. Eine bessere Koordination der jeweiligen Anlaufstellen mit Erfahrungsaustausch, gegenseitiger Unterstützung, gezielten Vermittlungsmöglichkeiten für Betroffene und eine alltagsnahe Begleitung sind hier wichtige Bausteine und können die Arbeit gegenseitig bereichern. Aus diesem Grund haben wir uns entschlossen, bundesweite SHO und relevante $\mathrm{SHG}$ aus den verschiedenen Gebieten der Verhaltensmedizin einem möglichst großen Kreis von Fachleuten und Selbsthilfe-Interessierten zugänglich zu machen. Therapeuten und Ärzte einerseits und SHG und SHO andererseits sollten im Gesundheitssystem nicht gegeneinander, sondern miteinander arbeiten. Auch gibt es funktionale Verbindungen zwischen Experten und Betroffenengruppen z.B. in Form von angeleiteter Selbsthilfe (Guided Self-help). Wir hoffen, auf diese Weise zur Verbesserung und Integration einzelner Elemente des Gesundheitssystems beizutragen.

\section{Material und Methode}

Für die Erhebung wurden 80 Selbsthilfevereinigungen aus dem breiten Spektrum der Verhaltensmedizin ausgewählt. Bei der Auswahl haben wir uns auf bundesweite Selbsthilfeorganisationen (SHO) und einige relevante Selbsthilfegruppen (SHG) beschränkt, da die Darstellung aller (lokalen) SHG den zur Verfügung stehenden Rahmen sprengen würde. Die beschriebenen SHO bieten zum Teil selbst bundesweit SHG an oder vermitteln deren Anschriften. Die ausgewählten Einrichtungen können grob folgenden Teilbereichen der Verhaltensmedizin zugeordnet werden:

- Allergie und Asthma,

- angeborene Behinderungen,

- Angehörige psychisch Kranker,

- Angststörungen,

- chronische Schmerzen,

- Erkrankungen des Bewegungsapparates,

- Ess-Störungen,

- gastrointestinale Erkrankungen und Inkontinenz,
- Hauterkrankungen,

- Hör- und Sprachbehinderungen,

- Lebenskrisen,

- neurologische Erkrankungen/Behinderungen,

- Persönlichkeitsstörungen und psychische Probleme,

- Sucht/Abhängigkeit

- sowie Zwangsstörungen.

Die Adressen für die Befragung wurden verschiedenen Verzeichnissen entnommen, z.B. dem Verzeichnis GRÜNE ADRESSEN [NAKOS, 1998/1999] der NAKOS (Nationale Kontakt- und Informationsstelle zur Anregung und Unterstützung von Selbsthilfegruppen). Die GRÜNEN ADRESSEN bieten einen repräsentativen Überblick über bundesweit tätige Selbsthilfevereinigungen und -einrichtungen und werden jährlich als Broschüre und CD-ROM, mit regelmäßiger Aktualisierung im Internet unter www.nakos.de veröffentlicht. Alle ausgewählten SHO und SHG verfolgen keine kommerziellen Zwecke. Bei fast allen im folgenden dargestellten Selbsthilfevereinigungen handelt es sich um gemeinnützige eingetragene Vereine (e.V.). Zwei der Einrichtungen sind gemeinnützige Gesellschaften mit beschränkter Haftung (gGmbH): Frankfurter Zentrum für Ess-Störungen (FZE) und SCHRITT für SCHRIT, Institut für ganzheitliche Kindesentwicklung (Hamburg). Nicht gemeinnützige GmbHs blieben unberücksichtigt. Bei SYNANON handelt es sich um eine Stiftung.

Für die Befragung der Selbsthilfevereinigungen wurde ein strukturierter Fragebogen entwickelt, der aus insgesamt 32 Fragen bestand. Die Antworten konnten offen und/oder als Forced-Choice notiert werden. Der Fragebogen gliederte sich in 7 Teile:

(1) Anschrift: Hier wurde die genaue Bezeichnung der Selbsthilfevereinigung, deren offizielle Abkürzung, der Ansprechpartner und die genaue Anschrift (Straße, Nummer, PLZ, Ort, Telefon, Telefax, E-Mail, InternetAdresse) erfasst.

(2) Kontaktaufnahme: Hier wurden alle realisierbaren Wege der Kontaktaufnahme (persönlich, telefonisch, schriftlich) und gegebenenfalls die dazugehörigen Sprechzeiten erhoben.

(3) Zielgruppe: Hier wurden die indizierten Personen- und / oder Störungsgruppen erfasst.

(4) Aufgaben und Ziele: Aufgaben und Ziele der Vereinigung wurden getrennt erfasst.

(5) Angebote: Hier wurden allgemeine Informationen, Beratung (Selbstbetroffene, Fachleute, Laien), Interessenvertretung der Betroffenen (Öffentlichkeitsarbeit, Veranstaltungen/Vorträge, Tagungen, Seminare/Kurse, Fortbildung, Medien) und Selbsthilfegruppen erfasst. Die Selbsthilfegruppen konnten näher spezifiziert werden: Zielgruppe, Gruppenform (offene Gruppe vs. geschlossene Gruppe), Teilnahmedauer (unbegrenzt vs. begrenzt), Gruppenziele, Leitung (ohne therapeutische Leitung vs. minimale therapeutische Leitung vs. Therapeuten-angeleitete Gruppe).

(6) Struktur der Einrichtung: Erfasst wurden Träger (Rechts- und Fachträger sowie die Rechtsform) der Einrichtung, Leitung, Personal, Zusammenarbeit (andere Selbsthilfevereinigungen, ambulante Beratungsstellen, Fachkliniken, niedergelassene Therapeuten, Ämter und Behörden, Krankenhäuser, sozialpsychiatrischer Dienst) und Finanzierung (öffentliche Zuschüsse, Eigenmittel, Mitgliedsbeiträge, Krankenkassen, private Spenden, Kursgebühren).

(7) Anmerkungen: Hier konnten ergänzende/weiterführende Angaben zu der Selbsthilfevereinigung gemacht werden.

Die SHO bzw. SHG wurden im Anschreiben über das Ziel der Befragung sowie die beabsichtigte Veröffentlichung in der Fachzeitschrift Verhaltenstherapie informiert. Säumige Selbsthilfevereinigungen wurden drei Wochen nach Erhebungsbeginn schriftlich und/oder telefonisch erneut gebeten, den Erhebungsbogen auszufüllen und zurück zu senden. In einigen Fällen wurden ergänzende Angaben zu den SHO bzw. SHG den jeweiligen Internet-Seiten der Selbsthilfevereinigungen entnommen. Die Erhebung wurde im ersten und zweiten Quartal 2000 durchgeführt. 


\section{Ergebnisse}

Insgesamt haben $90 \%$ der 70 angeschriebenen Selbsthilfevereinigungen geantwortet. Von diesen schickten 56 den Fragebogen ausgefüllt zurück, 5 legten anstelle des Fragebogens umfangreiches Informationsmaterial bei, 2 haben auf Informationen im Internet hingewiesen und 30 haben sowohl den Fragebogen ausgefüllt als auch zusätzlich Informationsmaterial beigelegt. Das Informationsmaterial bestand aus Broschüren, Informationsblättern und/oder Zeitschriften. Beide Informationsquellen wurden bei der Auswertung der Informationen berücksichtigt. Von den befragten Selbsthilfevereinigungen sind 36 bereits im Internet vertreten. Davon bieten 12 neben Informationen, Literatur, Links, Downloads und anderem auch Mailinglisten, Diskussions- und/oder Chat-Foren an. Die Darstellung der SHO und SHG erfolgt alphabetisch nach einzelnen Teilbereichen. Aus Platz- und Relevanzgründen wurden nicht alle erhobenen Informationen dargestellt. Innerhalb eines Bereiches wurden die Selbsthilfevereinigungen nach Postleitzahlen geordnet. Die Anonymen Raucher wünschten keine Veröffentlichung.

Darüber hinaus wurde die Darstellung der Ergebnisse wie folgt vereinfacht: Die Darstellung und Reihenfolge der Angaben entspricht der Struktur des Fragebogens; der schriftliche Weg der Kontaktaufnahme (Post, Fax, E-Mail) wurde nicht gesondert erwähnt; die unter Leitung und Personal aufgeführten Angaben beziehen sich bei den SHO auf die Geschäftsstelle.

Trotz aller Kooperation der meisten befragten Selbsthilfevereinigungen waren einige Schwierigkeiten zu überwinden (unvollständige Angaben, unleserliche Schrift, Verzögerung der Rücksendung, Informationsmaterial anstelle des Fragebogens). Aus diesem Grund können wir weder für die Vollständigkeit noch für die mitgeteilten Angaben eine Garantie übernehmen. Das nachfolgende Verzeichnis listet alle verhaltensmedizinischen Teilbereiche und Störungen auf, für die SHO oder SHG dargestellt werden.
Abhängige Frauen:

Alkoholabhängigkeit:

Alkoholkranke Ärzte:

Allergie:

Angeborene Behinderungen:

Angehörige psychisch Kranker:

Angehörige Suchtkranker:

Angststörungen:
Asthma:

Atemwegserkrankungen:

Borderline-Syndrom:

Chorea Huntington:

Chronische Schmerzen:

Colitis ulcerosa:

Cornelia-de-Lange-Syndrom:

Down-Syndrom:

Drogensucht:

Dystonie:

Emotions Anonymous:

Epilepsie:

Ess-Störungen:

Gastrointestinale Erkrankungen:

Geistige Behinderungen:

Hauterkrankungen:

Hirnverletzungen:

Hörsturz:

Hör- und Sprachbehinderungen:

Inkontinenz:

Lebenskrisen

Lippen- und Kiefer-Fehlbildungen:

Medikamentenabhängigkeit:

Migräne:

Morbus Crohn:

Morbus Menière:

Neurodermitis:

Persönlichkeitsstörungen:

Psoriasis:

Restless Legs:

Schlafapnoe:

Schlafstörungen:

Sexsucht:

Spielsucht:

Stottern:

Teilleistungsstörungen:

Tinnitus:

Torticollis:

Tourette-Syndrom:

Trauer:

Trichotillomanie:

Verlusterlebnisse:

Zöliakie:

Zwangsstörungen:
Tab. 1; Tab. 9

Tab. 1

Tab. 14

Tab. 13

Tab. 5a, b

Tab. 8

Tab. 2

Tab. 2

Tab. $15 \mathrm{a}, \mathrm{b}$

Tab. 6

Tab. 14

Tab. 12

Tab. 6

Tab. 7a, b

Tab. 8

Tab. 2

Tab. 1; Tab. 9

Tab. 12

Tab. 10

Tab. 10

Tab. 8

Tab. 11

Tab. 2

Tab. 5a; Tab. 15a, b

Tab. 5 b

Tab. 8

Tab. 10

Tab. 1; Tab. 9

Tab. 14

Tab. 9

Tab. 13

Tab. 13

Tab. 13

Tab. $15 \mathrm{c}$

Tab. $15 \mathrm{c}$

Tab. 10

Tab. 13

Tab. 10

Tab. 6

Tab. 12

Tab. 11

Tab. 16

Tab. 11

Tab. 1

Tab. 16
Tab. 4 


\section{Abschließende Bemerkungen}

Die dargestellten Selbsthilfevereinigungen bieten nur eine Auswahl der in der BRD tätigen SHO und SHG. Trotzdem verdeutlicht die Darstellung das umfangreiche Angebot der SHO und SHG sowie ihre Bedeutung für das heutige Gesundheitssystem. Mit unserer Darstellung hoffen wir, eine informative Übersicht und Beschreibung der Selbsthilfevereinigungen zur Verfügung zu stellen und auf diesem Weg die bereits bestehende Kooperation zwischen Fachleuten und SHO und SHG weiter $\mathrm{zu}$ fördern und $\mathrm{zu}$ unterstützen. Weitere Anschriften und Informationen von bundesweit tätigen Selbsthilfe-Vereinigungen und -Einrichtungen können dem Verzeichnis GRÜNE ADRESSEN entnommen werden. Einrichtungen, die fach- und themenübergreifend auf örtlicher Ebene über SHG informieren, bieten die ROTEN ADRESSEN an. Beide Verzeichnisse können angefordert werden bei:

Nationale Kontakt- und Informationsstelle zur Anregung und Unterstützung von Selbsthilfegruppen (NAKOS)

Albert-Achilles-Straße 65

D-10709 Berlin (Deutschland)

Tel. +49 30 89140-19, Fax -14

E-mailnakos@gmx.de.

www.nakos.de

Träger der NAKOS ist die Deutsche Arbeitsgemeinschaft Selbsthilfegruppen (DAG SHG) e.V., die auch zahlreiche Informationen zur Verfügung stellt:

Deutsche Arbeitsgemeinschaft Selbsthilfegruppen

(DAG SHG) e.V.

Friedrichstraße 28

D-35392 Gießen (Deutschland)

Tel. +49 641-74503, Fax -9945619
Auskunft über SHG zu spezifischen Problemen oder Erkrankungen gibt die Bundesarbeitsgemeinschaft Hilfe für Behinderte (BAGH) e.V. Sie ist ein Zusammenschluss von verschiedenen Selbsthilfeverbänden behinderter und chronisch kranker Menschen und ihrer Angehörigen in der BRD.

\section{Bundesarbeitsgemeinschaft}

Hilfe für Behinderte (BAGH) e.V.

Kirchfeldstraße 149

D-40215 Düsseldorf (Deutschland)

Tel. +49211310060

E-mailinfo@BAGH.de

www.BAGH.de

Zentrale Kontaktstellen für Selbsthilfevereinigungen in Österreich und der Schweiz sind:

Fonds Gesundes Österreich - SIGIS

Mariahilfer Straße 176

A-1150 Wien (Österreich)

Tel. +43 1895 0400-11, Fax -20

E-mail sigis@fgoe.org

www.fgoe.org

Selbsthilfezentrum Hinterhuus

Feldbergstraße 55

CH-4057 Basel (Schweiz)

Tel. +41 61692 81-00, Fax -77

E-mail hinterhuus@selbsthilfezentrum-bs.ch

www.selbsthilfezentrum-bs.ch

\section{Literatur}

Brunner E: Selbsthilfegruppen für Eßgestörte; in Hippius $\mathrm{H}$, Lauter $\mathrm{H}$, Greil W (Hrsg): Psychiatrie für die Praxis 12. Die Eßstörungen. München, MMV Medizin, 1990, pp 51-57.

Daum K-W, Matzat J, Moeller ML: Selbsthilfegruppen für chronisch Kranke; in Beckmann D, Davies-Osterkamp S, Scheer JW (Hrsg): Medizinische Psychologie. Berlin, Springer, 1982.

Daum K-W, Matzat J, Moeller ML: Psychologisch-therapeutische-Selbsthilfegruppen. Ein Forschungsbericht. Schriftenreihe des Bundesministers für Jugend, Familie und Gesundheit. Stuttgart, Kohlhammer, 1984. Döring N: Selbsthilfe, Beratung und Therapie im Internet; in Batinic B (Hrsg): Internet für Psychologen (Aufl 2). Göttingen, Hogrefe, 2000, pp 509-547. Fichter M: Kollektive Selbsthilfe - Alternative Modelle in Selbstorganisation; in Sommer G, Ernst H (Hrsg): Fortschritte der Klinischen Psychologie. Bd $11 \mathrm{Ge}-$ meindepsychologie. München, Urban und Schwarzenberg, 1976
KISS, Kontakt- und Informationsstellen für Selbsthilfegruppen, Behörde für Arbeit, Gesundheit und Soziales (BAGS) (Hrsg): Selbsthilfegruppen im Gesundheitswesen Raum Hamburg (Aufl 13). Freie und Hansestadt Hamburg, 1999.

Mathis H: Die Rolle von Selbsthilfegruppen und Selbsthilfeverbänden im Umstrukturierungsprozeß des Gesundheitswesens; in Deutsche Arbeitsgemeinschaft Selbsthilfegruppen e.V. (DAG SHG) (Hrsg): Selbsthilfegruppenjahrbuch 1999. Gießen, Focus, 1999.

Matzat J: Zur Rolle von Selbsthilfegruppen im Gesundheitswesen; in Hölling G, Petersen E (Hrsg): Zukunft der Gesundheit. Frankfurt/M., Mabuse, 1995.

Matzat J: Kontaktstellen für Selbsthilfegruppen - Professionelle Hilfe zur Selbsthilfe; in Günther P, Rohrmann E (Hrsg): Soziale Selbsthilfe. Alternative, Ergänzung oder Methode sozialer Arbeit? Heidelberg, Universitätsverlag C. Winter, 1999, pp 205-217.

Moeller ML: Selbsthilfegruppen in der Psychotherapie. Prax Psychother 1975;XX:181-193.
Moeller ML: Selbsthilfegruppen; in Bastine R, Fiedler PA, Grawe K, Schmidtchen S, Sommer G (Hrsg): Grundbegriffe der Psychotherapie. Weinheim, Edition Psychologie, 1982, pp 356-357.

Moeller ML: Möglichkeiten, Grenzen und Gefahren psychotherapeutisch arbeitender Selbsthilfegruppen. Psychother Med Psychol 1983;33:69-77.

Moeller ML: Selbsthilfegruppen in der Medizin; in Sessner H (Hrsg): Schriftenreihe der Bayrischen Landesärztekammer, Bd. 77, 1991, pp 216-223.

Moeller ML: Selbsthilfegruppen. Anleitungen und Hintergründe. Reinbek, Rowohlt, 1996.

NAKOS (Hrsg): Bundesweite Selbsthilfevereinigungen und relevante Institutionen, GRÜNE ADRESSEN, 1998/1999.

NAKOS (Hrsg): Lokale/Regionale Selbsthilfe-Unterstützung in Deutschland, ROTE ADRESSEN, 1998/ 1999 
Tab. 1. Selbsthilfevereinigungen: Allergie und Asthma

\begin{tabular}{|c|c|c|c|c|}
\hline Organisation & $\begin{array}{l}\text { Deutsche Hilfsorganisation Aller- } \\
\text { gie und Asthma (DHAA) e.V. }\end{array}$ & Deutsche Atemwegsliga e.V. & $\begin{array}{l}\text { Deutscher Allergie- und } \\
\text { Asthmabund (DAAB) e.V. }\end{array}$ & Allergiker Selbsthilfe e.V. \\
\hline Adresse & $\begin{array}{l}\text { - Bundesgeschäftsstelle - } \\
\text { Christa Buse } \\
\text { Bonusstraße } 32 \\
\text { 21079 Hamburg } \\
\text { Tel.040 76313-22, Fax -39 } \\
\text { dhaa-hamburg@t-online.de }\end{array}$ & $\begin{array}{l}\text { - Geschäftsstelle - } \\
\text { Dr. Uta Butt } \\
\text { Burgstraße } 12 \\
33175 \text { Bad Lippspringe } \\
\text { Tel. 05252 9336-15, Fax -16 } \\
\text { atemwegsliga.u.butt@t-online.de } \\
\text { atemwegsliga.lippspringe } \\
\text { @t-online.de } \\
\text { www.atemwegsliga.de } \\
\text { (Diskussionsforum) }\end{array}$ & $\begin{array}{l}\text { - Bundesgeschäftsstelle - } \\
\text { Hindenburgstraße } 110 \\
\text { 41061 Mönchengladbach } \\
\text { Tel. 02161 8149-40, Fax -430 } \\
\text { info@daab.de } \\
\text { www.daab.de }\end{array}$ & $\begin{array}{l}\text { Thomas Weigert } \\
\text { Postfach } 1665 \\
65766 \text { Kelkheim } \\
\text { Tel. u. Fax } 06195910674 \\
\text { Allergiker-Selbsthilfe@t-online.de }\end{array}$ \\
\hline Kontaktaufnahme & $\begin{array}{l}\text { persönlich u. telefonisch } \\
\text { Di-Do 11:00-18:00 Uhr }\end{array}$ & k.A. & $\begin{array}{l}\text { persönlich nach Vereinbarung; } \\
\text { telefonisch tägl. 9:30-12:30 Uhr } \\
\text { (Beratungstel.: 02161 10207); } \\
\text { Mo 10:00-12:00 u. 14:00-16:00 Uhr } \\
\text { Beratung bei } \\
\text { Nahrungsmittelallergie; } \\
\text { Do 10:00-12:00 u. 14:00-16:00 Uhr } \\
\text { Beratung zu Haut u. Asthma } \\
\text { (02161 814940) }\end{array}$ & $\begin{array}{l}\text { persönliche Sprechzeiten nach } \\
\text { Vereinbarung; telefonisch Mi u. Fr } \\
\text { 9:00-12:00 u. Do 19:00-21:00 Uhr }\end{array}$ \\
\hline Zielgruppe & $\begin{array}{l}\text { Menschen, die unter Allergie, } \\
\text { Asthma o. Neurodermitis leiden u. } \\
\text { deren Angehörige sowie Freunde; } \\
\text { andere Ratsuchende }\end{array}$ & $\begin{array}{l}\text { Ärzte, die Patienten mit Atem- } \\
\text { wegserkrankungen betreuen; } \\
\text { Patienten mit Atemwegserkran- } \\
\text { kungen }\end{array}$ & $\begin{array}{l}\text { Allergiker, Asthmatiker u. Neuro- } \\
\text { dermitiker }\end{array}$ & $\begin{array}{l}\text { Kinder, Jugendliche und Erwach- } \\
\text { sene mit Asthma, Neurodermitis, } \\
\text { Allergien u. Zöliakie }\end{array}$ \\
\hline Aufgaben & $\begin{array}{l}\text { Rat u. Hilfe; psychosoziale } \\
\text { Beratung; Gesundheitserziehung; } \\
\text { Interessenvertretung }\end{array}$ & $\begin{array}{l}\text { Fortbildung von Ärzten; } \\
\text { Information von Patienten u. } \\
\text { Öffentlichkeit; Unterstützung von } \\
\text { Programmen zur Prophylaxe } \\
\text { u. Früherkennung; Förderung der } \\
\text { Qualitätssicherung in Diagnostik } \\
\text { u. Therapie }\end{array}$ & Beratung u. Information & Aufklärung, Info u. Beratung \\
\hline Angebote & $\begin{array}{l}\text { allg. Info; Beratung durch Selbst- } \\
\text { betroffene u. Fachleute; Interes- } \\
\text { senvertretung der Betroffenen } \\
\text { (Öff, Ver / Vor, Tag, Sem / Kur, } \\
\text { Fort, Med: div. Ratgeber); } \\
\text { bundesweit SHG (offene Gruppe; } \\
\text { Teilnahmedauer begr. nach } \\
\text { Absprache; Ziele: Thematisierung, } \\
\text { der aus der Erkrankung resultie- } \\
\text { renden Konflikte, Erfassung fami- } \\
\text { liärer Kommunikationsstrukturen, } \\
\text { Erarbeitung von selbst. Lösungs- } \\
\text { vorschlägen zur Konfliktbewälti- } \\
\text { gung; Therapeuten-angeleitete } \\
\text { Gruppe) }\end{array}$ & $\begin{array}{l}\text { allg. Info (Asthma-Tagebücher, } \\
\text { Broschüren, Informationsblätter); } \\
\text { Beratung durch Fachleute }\end{array}$ & $\begin{array}{l}\text { allg. Info; Beratung durch } \\
\text { Fachleute; Interessenvertretung } \\
\text { der Betroffenen (Öff, Ver: } \\
\text { AllergieMobil fährt durch die } \\
\text { BRD / Vor, Tag: jährl. Allergie- } \\
\text { und Asthmatag in Bonn, Sem / } \\
\text { Kur, Fort, Med: Merkblätter, } \\
\text { Artikel, Ratgeber, Magazin } \\
\text { «Allergie konkret» } 4 \times \text { jährl.); } \\
\text { bundesweit Landes- u. Ortsver- } \\
\text { bände, die vor Ort Veranstaltun- } \\
\text { gen organisieren (Asthma- } \\
\text { schulungen, Gesprächsgruppen) }\end{array}$ & $\begin{array}{l}\text { allg. Info; Beratung durch Selbst- } \\
\text { betroffene u. Fachleute; Interes- } \\
\text { senvertretung der Betroffenen } \\
\text { (Öff, Ver / Vor, Tag, Sem / Kur, } \\
\text { Fort, Med: etwa } 450 \text { Broschüren } \\
\text { zum Thema, Mitgliederzeitung } \\
\text { «Allergie-Express» } 4 \times \text { jährl.); } \\
\text { «Spatzentreff» f. Eltern allergie- } \\
\text { kranker Kinder (offene Gruppe, } \\
\text { Teilnahmedauer unbegr., Ziele: } \\
\text { Erfahrungsaustausch u. } \\
\text { Informationsvermittlung, ohne } \\
\text { therapeutische Leitung, etwa } \\
6 \text { Mütter mit Kindern) }\end{array}$ \\
\hline Leitung & $\begin{array}{l}\text { Vorstand (besteht aus Personen } \\
\text { mit medizinischen, naturwissen- } \\
\text { schaftlichen u. juristischen } \\
\text { Kenntnissen) }\end{array}$ & $\begin{array}{l}\text { Prof. Dr. Heinrich Worth } \\
\text { (Vorsitzender); Dr. Uta Butt } \\
\text { (Koordinatorin) }\end{array}$ & Vorstand & Thomas Weigert (Vorsitzender) \\
\hline Personal & $\begin{array}{l}\text { Ärzte; Dipl.-Soz.-Päd.; } \\
\text { Dipl.-Soz.-Arb.; Dipl.-Psych.; } \\
\text { Dipl.-Oecotroph. }\end{array}$ & $\begin{array}{l}1 \text { Assistentin der Geschäftsstelle } \\
\text { (Med. Dokumentationsassistentin) }\end{array}$ & $\begin{array}{l}\text { Dipl.-Chem.; Dipl.-Oecotroph.; } \\
\text { Dipl.-Päd.; ehrenamtliche } \\
\text { Mitarbeiter vor Ort }\end{array}$ & Vorstandsmitglieder u. wiss. Beirat \\
\hline Zusammenarbeit & $\begin{array}{l}\text { Kindernetzwerk e.V.; Behinderten } \\
\text { Arbeitsgemeinschaft e.V.; } \\
\text { ambulante Beratungsstellen; } \\
\text { niedergelassene Therapeuten; } \\
\text { Fachkliniken; Krankenhäuser; } \\
\text { Ämter u. Behörden; Kinderheime } \\
\text { u. -gärten; Schulen }\end{array}$ & andere SHG; Fachkliniken & k.A. & $\begin{array}{l}\text { SHO; ambulante Beratungsstellen; } \\
\text { niedergelassene Therapeuten; } \\
\text { Fachkliniken; Krankenhäuser; } \\
\text { Ämter u. Behörden; sozial- } \\
\text { psychiatrischer Dienst }\end{array}$ \\
\hline Finanzierung & $\begin{array}{l}\text { öffentl. Zuschüsse; Eigenmittel; } \\
\text { Mitgliedsbeiträge; Krankenkassen; } \\
\text { private Spenden; Kursgebühren }\end{array}$ & $\begin{array}{l}\text { Mitgliedsbeiträge; private Spen- } \\
\text { den; Kursgebühren }\end{array}$ & Mitgliedsbeiträge; private Spenden & $\begin{array}{l}\text { öffentl. Zuschüsse; Mitglieds- } \\
\text { beiträge; Krankenkassen; private } \\
\text { Spenden; Kursgebühren }\end{array}$ \\
\hline
\end{tabular}

allg. Info: allgemeine Informationen; begr.: begrenzt; div.: diverse; Fort: Fortbildung; k.A.: keine (näheren) Angaben; Kur: Kurse; Med: Medien; öffentl.: öffentlich; Öff: Öffentlichkeitsarbeit; Sem: Seminare; SH: Selbsthilfe; SHG: Selbsthilfegruppe(n); SHO: Selbsthilfeorganisation(en); Tag: Tagungen; unbegr.: unbegrenzt; Ver: Veranstaltungen; Vor: Vorträge. 
Tab. 2. Selbsthilfevereinigungen: Angeborene Behinderungen

\begin{tabular}{|c|c|c|c|c|}
\hline Organisation & Arbeitskreis Down-Syndrom e.V. & $\begin{array}{l}\text { Bundesvereinigung Lebenshilfe } \\
\text { für Menschen mit geistiger } \\
\text { Behinderung e.V. }\end{array}$ & $\begin{array}{l}\text { Selbsthilfevereinigung für } \\
\text { Lippen-Gaumen-Fehlbildungen } \\
\text { e.V. }\end{array}$ & $\begin{array}{l}\text { Arbeitskreis Cornelia de Lange- } \\
\text { Syndrom (CdLS) e.V. }\end{array}$ \\
\hline Adresse & $\begin{array}{l}\text { Rita Lawrenz } \\
\text { Gadderbaumer Straße } 28 \\
33602 \text { Bielefeld } \\
\text { Tel. 0521-4429 98, } \\
\text { Fax -9429 } 04 \\
\text { ak@down-syndrom.org } \\
\text { www.down-syndrom.org }\end{array}$ & $\begin{array}{l}\text { - Bundeszentrale - } \\
\text { Dr. Theo Frühauf } \\
\text { Raiffeisenstraße } 18 \\
35043 \text { Marburg } \\
\text { Tel. 06421 49-10, Fax -1167 } \\
\text { Bundeszentrale@Lebenshilfe.de } \\
\text { www.lebenshilfe.de }\end{array}$ & $\begin{array}{l}\text { Wolfgang Rosenthal Gesellschaft } \\
\text { Regine Tödt } \\
\text { Hauptstraße } 184 \\
\text { 35625 Hüttenberg } \\
\text { Tel. 06403-5575, Fax -9267 } 27 \\
\text { wrg-huettenberg@t-online.de } \\
\text { www.t-online.de/home/wrg- } \\
\text { huettenberg }\end{array}$ & $\begin{array}{l}\text { Jürgen Kegel } \\
\text { Ober-Liebersbach } 27 \\
\text { 69509 Mörlenbach } \\
\text { Tel. 06209-6650, Fax -713193 } \\
\text { Kegel-Moerlenbach@t-online.de }\end{array}$ \\
\hline Kontaktaufnahme & k.A. & $\begin{array}{l}\text { persönlich nach Vereinbarung; } \\
\text { telefonisch 8:00-12:00 u. } \\
\text { 14:00-16:00 Uhr }\end{array}$ & $\begin{array}{l}\text { persönlich u. telefonisch } \\
\text { Mo-Fr 9:00-12:00 Uhr; } \\
\text { Gesprächstermine nach } \\
\text { Vereinbarung }\end{array}$ & telefonisch tägl. ab 17:00 Uhr \\
\hline Zielgruppe & $\begin{array}{l}\text { Menschen mit Down-Syndrom, } \\
\text { deren Eltern u. Freunde; Fachleute } \\
\text { u. andere Interessierte }\end{array}$ & $\begin{array}{l}\text { geistig behinderte Kinder, } \\
\text { Jugendliche u. Erwachsene sowie } \\
\text { deren Angehörige; interessierte } \\
\text { Fachleute }\end{array}$ & $\begin{array}{l}\text { Kinder u. Erwachsene mit Lippen-, } \\
\text { Kiefer- u. Gaumenspalten sowie } \\
\text { Eltern von betroffenen Kindern }\end{array}$ & $\begin{array}{l}\text { betroffene Eltern; Ärzte; } \\
\text { Therapeuten; Kliniken u. } \\
\text { Forschungseinrichtungen }\end{array}$ \\
\hline Aufgaben & $\begin{array}{l}\text { Information der Öffentlichkeit } \\
\text { über Menschen mit Down- } \\
\text { Syndrom; Abbau von «Vor- } \\
\text { Urteilen»; Eintreten f. Hilfe f. } \\
\text { Menschen mit Down-Syndrom }\end{array}$ & $\begin{array}{l}\text { die Lebenshilfe vertritt die Rechte } \\
\text { u. Interessen geistig behinderter } \\
\text { Menschen; sie bietet Beratung u. } \\
\text { Unterstützung f. betroffene Eltern } \\
\text { an }\end{array}$ & $\begin{array}{l}\text { Hilfe nach der Geburt; Aufklärung } \\
\text { der Öffentlichkeit; Verbesserung } \\
\text { der Kooperation mit Experten; } \\
\text { Beratung }\end{array}$ & $\begin{array}{l}\text { Hilfe u. Info f. betroffene } \\
\text { Familien; Öffentlichkeitsarbeit; } \\
\text { Verbesserung der Zusammen- } \\
\text { arbeit mit Ärzten, Kliniken u. } \\
\text { Forschungseinrichtungen }\end{array}$ \\
\hline Angebote & $\begin{array}{l}\text { allg. Info; Interessenvertretung } \\
\text { der Betroffenen (Öff, Ver / Vor, } \\
\text { Med: «Mitteilungen» } 4 \times \text { jährl., } \\
\text { Info-Blätter, Literaturverzeichnis, } \\
\text { Poster, Aufkleber); Vermittlung } \\
\text { von Kontakten zu Eltern, } \\
\text { Fachleuten u. Elterngruppen; } \\
\text { Treffen von Kindern u. Eltern } \\
\text { (verschiedene Orte) }\end{array}$ & $\begin{array}{l}\text { die Lebenshilfe unterhält in der } \\
\text { ganzen BRD } 3000 \text { Einrichtungen } \\
\text { u. mobile bzw. ambulante Dienste } \\
\text { zur Förderung geistig behinderter } \\
\text { Menschen u. zur Unterstützung } \\
\text { ihrer Angehörigen (z.B. Früh- } \\
\text { förderstellen, Kindergärten u. } \\
\text { Schulen, Werk- u. Wohnstätten); } \\
\text { Fort- u. Weiterbildung f. Betrof- } \\
\text { fene u. Mitarbeiter verschiedener } \\
\text { Einrichtungen; sie bietet Bücher } \\
\text { u. Broschüren, eine Fachzeitschrift } \\
\text { u. die «Lebenshilfe-Zeitung» an }\end{array}$ & $\begin{array}{l}\text { allg Info; Beratung durch Selbst- } \\
\text { betroffene, Fachleute u. Laien; } \\
\text { Interessenvertretung der Betrof- } \\
\text { fenen (Öff, Ver / Vor, Tag, Sem / } \\
\text { Kur, Fort: f. ehrenamtliche } \\
\text { Mitarbeiter, Med: Informations- } \\
\text { broschüren); SHG; etwa } 120 \\
\text { regionale Kontaktgruppen }\end{array}$ & $\begin{array}{l}\text { allg Info; Beratung durch Selbst } \\
\text { betroffene, Fachleute u. Laien; } \\
\text { Interessenvertretung der Betrof- } \\
\text { fenen (Öff, Ver / Vor, Tag, Med); } \\
\text { SHG (offene Gruppe, Teilnahme- } \\
\text { dauer unbegr., die SHG besteht } \\
\text { aus } 126 \text { betroffenen Familien) }\end{array}$ \\
\hline Leitung & Vorstand & Günther Jaspert (Vorsitzender) & $\begin{array}{l}\text { hauptamtlich angestellte Dipl.- } \\
\text { Soz.-Päd.; ehrenamtliche } \\
\text { Mitarbeiter }\end{array}$ & $\begin{array}{l}\text { Jürgen Kegel (Vorsitzender) in } \\
\text { Zusammenarbeit mit dem } \\
\text { Vorstand }\end{array}$ \\
\hline Personal & k.A. & k.A. & k.A. & $\begin{array}{l}\text { Vorstand; Kassiererin; } \\
\text { Schriftführerin }\end{array}$ \\
\hline Zusammenarbeit & $\begin{array}{l}\text { mit Personen u. Institutionen, } \\
\text { die gleiche o. ähnliche Ziele verfol- } \\
\text { gen: Ärzte, Pädagogen, Behörden, } \\
\text { Verbände, wiss. Institute, Einrich- } \\
\text { tungen f. Ausbildung, Arbeit, } \\
\text { Wohnen u. Leben; Organisationen } \\
\text { u. Elternvereinigungen }\end{array}$ & k.A. & $\begin{array}{l}\text { Bundesarbeitsgemeinschaft Hilfe } \\
\text { für Behinderte; Paritätischer } \\
\text { Wohlfahrtsverband }\end{array}$ & k.A. \\
\hline Finanzierung & k.A & k.A. & $\begin{array}{l}\text { öffentl. Zuschüsse; Mitglieds- } \\
\text { beiträge; private Spenden }\end{array}$ & $\begin{array}{l}\text { öffentl. Zuschüsse; Eigenmittel; } \\
\text { Mitgliedsbeiträge; private } \\
\text { Spenden; Spendendosen }\end{array}$ \\
\hline
\end{tabular}

allg. Info: allgemeine Informationen; begr.: begrenzt; div.: diverse; Fort: Fortbildung; k.A.: keine (näheren) Angaben; Kur: Kurse; Med: Medien; öffentl.: öffentlich; Öff: Öffentlichkeitsarbeit; Sem: Seminare; SH: Selbsthilfe; SHG: Selbsthilfegruppe(n); SHO: Selbsthilfeorganisation(en); Tag: Tagungen; unbegr.: unbegrenzt; Ver: Veranstaltungen; Vor: Vorträge. 
Tab. 3. Selbsthilfevereinigungen: Angehörige psychisch Kranker

$\begin{array}{ll}\text { Organisation } & \text { Bundesverband der Angehörigen psychisch Kranker (BApK) e.V. } \\ \text { Adresse } & \begin{array}{l}\text { Thomas-Mann-Straße 49 a } \\ \text { 53111 Bonn } \\ \text { Tel. 0228-6326 46, Fax -6580 } 63 \\ \text { bapk@psychiatrie.de } \\ \text { www.psychiatrie.de (Expertenforum; Mailingliste) }\end{array} \\ \text { Kontaktaufnahme } & \text { telefonisch Mo-Do 9:00-14:00 Uhr } \\ & \text { Angehörige von psychisch Kranken } \\ \text { Zielgruppe } & \begin{array}{l}\text { politische Einflussnahme auf die Bundesgesetzgebung im Interesse der } \\ \text { Eufgaben } \\ \text { Situation der Familien; Darstellung der Chancen u. Defizite im Versor- } \\ \text { gungssystem der Psychiatrie; Anregung u. Beratung psychiatrischer }\end{array} \\ & \begin{array}{l}\text { Forschung; Veröffentlichung u. Vermittlung von Literatur; Anregung u. } \\ \text { Beratung psychiatrischer Forschung }\end{array}\end{array}$

Angebote allg Info über örtliche Angehörigengruppen; Interessenvertretung der Betroffenen (Öff, Ver / Vor, Tag, Sem / Kur, Med); bundesweit SHG

$\begin{array}{ll}\text { Leitung } & \begin{array}{l}\text { Vorstandsgremium (bestehend aus Angehörigen von psychisch } \\ \text { Kranken) }\end{array} \\ \text { Personal } & \begin{array}{l}\text { 1 Referentin u. 1 Sachbearbeiterin } \\ \text { Zusammenarbeit }\end{array} \\ \begin{array}{l}\text { Bundesverband der Psychiatrie-Erfahrenen e.V.; Dachverband psycho- } \\ \text { sozialer Hilfvereinigungen e.V.; Ämter u. Behörden }\end{array}\end{array}$

Finanzierung sozialer Hilfvereinigungen e.V.; Ämter u. Behörden

öffentl. Zuschüsse; Mitgliedsbeiträge; Krankenkassen; private Spenden; Spenden aus Industrie
Aktionsgemeinschaft der Angehörigen psychisch Kranker, ihrer Freunde und Förderer e.V.

\section{Eva Vieweg}

Landsberger Straße 135 / II

80339 München

Tel. 089-502 4673, Fax -70 1178

persönlich u. telefonisch Mo u. Do 16:00-18:00; Di u. Fr 10:00-12:00 Uhr

Angehörige von psychisch Kranken

Hilfe u. Information über die Krankheit, Therapie, Beschäftigungsmög lichkeiten u. juristische Fragen

allg. Info; Beratung durch Selbstbetroffene, Fachleute u. Laien; Interessenvertretung der Betroffenen (Öff, Ver / Vor, Tag); SHG 1 (offene Gruppe, Teilnahmedauer unbegr., ohne therapeutische Leitung, 5-15 Teilnehmer); SHG 2 (offene Gruppe, Teilnahmedaue unbegr., Leitung durch eine Fachärztin, 10-14 Teilnehmer)

Vorstand aus 7 Personen (1. Vorsitzende Eva Vieweg)

2 Bürokräfte u. ehrenamtliche Mitarbeiter

ambulante Beratungsstellen; niedergelassene Therapeuten; Fachkliniken; Krankenhäuser; Ämter u. Behörden; sozialpsychiatrischer Dienst

öffentl. Zuschüsse; Eigenmittel; Mitgliedsbeiträge; private Spenden

allg. Info: allgemeine Informationen; begr.: begrenzt; div.: diverse; Fort: Fortbildung; k.A.: keine (näheren) Angaben; Kur: Kurse; Med: Medien; öffentl.: öffentlich; Öff: Öffentlichkeitsarbeit; Sem: Seminare; SH: Selbsthilfe; SHG: Selbsthilfegruppe(n); SHO: Selbsthilfeorganisation(en); Tag: Tagungen; unbegr.: unbegrenzt; Ver: Veranstaltungen; Vor: Vorträge. 
Tab. 4. Selbsthilfevereinigungen: Angststörungen

\begin{tabular}{|c|c|c|c|}
\hline Organisation & $\begin{array}{l}\text { Agoraphobie e.V., Angstzentrum Berlin Beratungs- } \\
\text { stelle bei Angst, Panik und Phobien }\end{array}$ & $\begin{array}{l}\text { Deutsche Angststörungenhilfe und } \\
\text {-Selbsthilfe (DASH) e.V. }\end{array}$ & $\begin{array}{l}\text { Münchener Angsthilfe und -Selbsthilfe } \\
\text { (MASH) e.V. }\end{array}$ \\
\hline Adresse & $\begin{array}{l}\text { Herr und Frau Hartmann, Frau Kropf } \\
\text { Taunusstraße } 5 \\
12161 \text { Berlin } \\
\text { Tel. u. Fax } 0308515824 \\
\text { Angstzentrum.Berlin@t-online.de }\end{array}$ & $\begin{array}{l}\text { Gerhard Schick } \\
\text { Bayerstraße } 77 \text { a } \\
80335 \text { München } \\
\text { Tel. } 0895440 \text { 37-75, Fax }-76\end{array}$ & $\begin{array}{l}\text { Bayerstraße } 77 \text { a } \\
80335 \text { München } \\
\text { Tel. } 0895438080\end{array}$ \\
\hline Kontaktaufnahme & $\begin{array}{l}\text { persönlich Mo 9:00-13:00, Mi 13:00-18:00 } \\
\text { u. Do 17:00-19:30 Uhr; telefonisch Mo 9:00-13:00, } \\
\text { Mi 13:00-18:00, Do 17:00-19:30 u. Fr 9:00-13:00 Uhr }\end{array}$ & k. A. & $\begin{array}{l}\text { telefonisch Mo u. Do 15:00-18:00; } \\
\text { Mi 11:00-14:00 Uhr }\end{array}$ \\
\hline Zielgruppe & $\begin{array}{l}\text { Angsterkrankte u. deren Angehörige; Mitarbeiter } \\
\text { aus psychosozialen Einrichtungen u. Interessierte }\end{array}$ & $\begin{array}{l}\text { Menschen mit Angststörungen, die außer- } \\
\text { halb von München wohnen }\end{array}$ & $\begin{array}{l}\text { Menschen mit Angststörungen aus dem } \\
\text { Raum München }\end{array}$ \\
\hline Aufgaben & $\begin{array}{l}\text { Beratung bei Angststörungen u. bzgl. Behand- } \\
\text { lungsmöglichkeiten sowie SHG; Diagnostik u. } \\
\text { Therapieindikation; Anleitung von SHG; Beratung } \\
\text { von Angehörigen u. Mitarbeitern aus der psycho- } \\
\text { sozialen Arbeit }\end{array}$ & $\begin{array}{l}\text { Bereitstellung einer Plattform, die Men- } \\
\text { schen mit Angststörungen Möglichkeiten } \\
\text { eröffnet, ihre Symptomatik, Problematik } \\
\text { und Beeinträchtigung durch SH, gegensei- } \\
\text { tige Hilfe u. Fremdhilfe abzubauen }\end{array}$ & Beratung u. Information \\
\hline Angebote & $\begin{array}{l}\text { allg. Info (Literaturempfehlungen, bundesweite } \\
\text { Adressenvermittlung von störungsspezifischen } \\
\text { SHG); Beratung durch Fachleute; Interessenvertre- } \\
\text { tung der Betroffenen (Öff, Ver / Vor, Sem / Kur, } \\
\text { Fort, Med); SHG } 1 \text { (offene Gruppe fortlaufend, } \\
\text { Teilnahmedauer unbegr., Ziele: Abbau von Isola- } \\
\text { tion, sozialem Rückzug u. Informationsdefiziten, } \\
\text { Entwicklung von Bewältigungsstrategien; Thera- } \\
\text { peuten-angeleitete Gruppe); SHG } 2 \text { (geschlossene } \\
\text { Gruppe, Teilnahmedauer begr., Ziele u. Leitung wie } \\
\text { SHG 1) }\end{array}$ & $\begin{array}{l}\text { allg. Info; Beratung durch Selbstbetroffene } \\
\text { u. Fachleute; Interessenvertretung der } \\
\text { Betroffenen (Öff, Ver / Vor, Tag, Sem / } \\
\text { Kur, Fort, Med: «daz - Deutsche Angst- } \\
\text { Zeitschrift»); SHG (Eintritt nach Austritt } \\
\text { eines Teilnehmers, Teilnahmedauer unbe- } \\
\text { grenzt, ohne therapeutische Leitung, max. } \\
12 \text { Teilnehmer); Vermittlung von SHG im } \\
\text { gesamten Bundesgebiet }\end{array}$ & $\begin{array}{l}\text { allg. Info (Kontaktadressen von örtlichen } \\
\text { oder umliegenden SHG); Interessenver- } \\
\text { tretung der Betroffenen (Med: «daz- } \\
\text { Deutsche Angst-Zeitschrift»); SHG; } \\
\text { Übungs- u. therapeutische Gruppen }\end{array}$ \\
\hline Leitung & Herr u. Frau Hartmann; Frau Kropf & Gerhard Schick & Gerhard Schick \\
\hline Personal & $\begin{array}{l}\text { Dipl.-Psych. mit Zusatzausbildung als Gruppen- } \\
\text { leiterInnen }\end{array}$ & $\begin{array}{l}1 \text { Verwaltungsangestellte; } \\
13 \text { Gruppenleiter }\end{array}$ & k.A. \\
\hline Zusammenarbeit & $\begin{array}{l}\text { Berliner Selbsthilfe-, Kontakt- u. Informations- } \\
\text { stellen; ambulante Beratungsstellen; } \\
\text { niedergelassene Therapeuten; Fachkliniken; } \\
\text { sozialpsychiatrischer Dienst }\end{array}$ & $\begin{array}{l}\text { andere Selbsthilfevereinigungen; } \\
\text { ambulante Beratungsstellen; nieder- } \\
\text { gelassene Therapeuten; Fachkliniken; } \\
\text { Krankenhäuser; Ämter u. Behörden; } \\
\text { sozialpsychiatrischer Dienst }\end{array}$ & $\begin{array}{l}\text { andere Selbsthilfevereinigungen; } \\
\text { ambulante Beratungsstellen; nieder- } \\
\text { gelassene Therapeuten; Fachkliniken; } \\
\text { Krankenhäuser; Ämter u. Behörden; } \\
\text { sozialpsychiatrischer Dienst }\end{array}$ \\
\hline Finanzierung & öffentl. Zuschüsse; private Spenden & öffentl. Zuschüsse; private Spenden & öffentl. Zuschüsse; private Spenden \\
\hline
\end{tabular}

allg. Info: allgemeine Informationen; begr.: begrenzt; div.: diverse; Fort: Fortbildung; k.A.: keine (näheren) Angaben; Kur: Kurse; Med: Medien; öffentl.: öffentlich; Öff: Öffentlichkeitsarbeit; Sem: Seminare; SH: Selbsthilfe; SHG: Selbsthilfegruppe(n); SHO: Selbsthilfeorganisation(en); Tag: Tagungen; unbegr.: unbegrenzt; Ver: Veranstaltungen; Vor: Vorträge. 
Tab. 5a. Selbsthilfevereinigungen: Chronische Schmerzen I

\begin{tabular}{|c|c|c|c|c|}
\hline Organisation & Deutsche Schmerzhilfe (DSH) e.V. & $\begin{array}{l}\text { Hilfe für medikamentenabhängige } \\
\text { Schmerzkranke (HIMS) e.V. }\end{array}$ & Aktive SchmerzHilfe (ASH) e.V. & Deutsche SCHMERZLIGA e.V. \\
\hline Adresse & $\begin{array}{l}\text { - Bundesverband - } \\
\text { Rüdiger Fabian } \\
\text { Sietwende } 20 \\
\text { 21720 Grünendeich } \\
\text { Tel.04142 8104-34, Fax -35 } \\
\text { schmerzhilfe@t-online.de }\end{array}$ & $\begin{array}{l}\text { Ingrid Kording } \\
\text { Ascherfeld } 11 \\
28757 \text { Bremen } \\
\text { Tel. } 0421 \text { 6514-95, Fax }-30\end{array}$ & $\begin{array}{l}\text { Hiltrud Lisken } \\
\text { Postfach } 100116 \\
\text { 47701 Krefeld } \\
\text { Tel. u. Fax } 02151761797\end{array}$ & $\begin{array}{l}\text { Rita Wanninger } \\
\text { Hainstraße } 2 \\
61476 \text { Kronberg } \\
\text { Tel. } 0700375 \text { 375-375, Fax -38 } \\
\text { www.dsl-ev.de }\end{array}$ \\
\hline Kontaktaufnahme & $\begin{array}{l}\text { telefonisch Mo-Fr 9:00-12:30 } \\
\text { u. Mo-Do 14:30-16:00 Uhr }\end{array}$ & $\begin{array}{l}\text { persönlich Mo-Fr 10:00-13:00 } \\
\text { u. 17:00-20:00 Uhr; telefonisch } \\
\text { Mo-Sa 10:00-13:00 } \\
\text { u. 17:00-20:00 Uhr }\end{array}$ & $\begin{array}{l}\text { persönlich nach Vereinbarung; } \\
\text { telefonisch Di 18:00-19:30 Uhr }\end{array}$ & telefonisch Mo-Fr 9:00-12:00 Uhr \\
\hline Zielgruppe & chronisch Schmerzkranke & chronisch Schmerzkranke & $\begin{array}{l}\text { chronisch Schmerzbetroffene; von } \\
\text { chronischem Schmerz bedrohte } \\
\text { Menschen; Angehörige; Fachleute } \\
\text { (Mediziner, Dipl.-Psych. u. a. } \\
\text { Therapeuten); Interessierte }\end{array}$ & $\begin{array}{l}\text { chronisch Schmerzkranke u. deren } \\
\text { Angehörige }\end{array}$ \\
\hline Aufgaben & $\begin{array}{l}\text { Verbesserung des Informations- } \\
\text { standes der Betroffenen; } \\
\text { Verbesserung der medizinischen } \\
\text { und der psychologischen / psycho- } \\
\text { therapeutischen sowie sozialen } \\
\text { Versorgung von Schmerzpatienten; } \\
\text { Aufbrechen der Isolation der } \\
\text { Betroffenen }\end{array}$ & $\begin{array}{l}\text { Aufklärung in öffentlichen } \\
\text { Veranstaltungen; Zusammenarbeit } \\
\text { mit Experten; telefonische } \\
\text { Beratung; Öffentlichkeitsarbeit }\end{array}$ & $\begin{array}{l}\text { Förderung des Erfahrungs- } \\
\text { austausches, der Information und } \\
\text { Beratung zw. Betroffenen, } \\
\text { Angehörigen, Fachleuten u. } \\
\text { Interessierten durch regelmäßige } \\
\text { Treffen, Begleitung, Informations- } \\
\text { u. Bildungsangebote }\end{array}$ & $\begin{array}{l}\text { Information; Unterstützung u. } \\
\text { Förderung von SHG }\end{array}$ \\
\hline Angebote & $\begin{array}{l}\text { allg. Info (Nachweis von kom- } \\
\text { petenten Schmerztherapeuten } \\
\text { in Wohnortnähe f. chronische } \\
\text { Schmerzpatienten); Beratung } \\
\text { durch Fachleute; Interessen- } \\
\text { vertretung der Betroffenen } \\
\text { (Öff, Ver / Vor, Tag, Sem / Kur, } \\
\text { Fort, Med: Zeitschrift «Schmerz- } \\
\text { hilfe»); Gründung u. Unterstüt- } \\
\text { zung von SHG }\end{array}$ & $\begin{array}{l}\text { allg. Info (Verzeichnis von } \\
\text { Schmerztherapeuten, -Kliniken u. } \\
\text {-Ambulanzen f. das gesamte } \\
\text { Bundesgebiet); Beratung durch } \\
\text { Selbstbetroffene u. Fachleute; } \\
\text { Interessenvertretung der Betroffe- } \\
\text { nen (Öff, Ver / Vor, Tag, Sem / } \\
\text { Kur, Fort, Med: Faltblätter) }\end{array}$ & $\begin{array}{l}\text { allg. Info; Beratung durch Selbst- } \\
\text { betroffene, Fachleute u. Laien; } \\
\text { Interessenvertretung der Betroffe- } \\
\text { nen (Öff, Ver / Vor, Tag, Sem / } \\
\text { Kur, Fort: f. ehrenamtliche Mitar- } \\
\text { beiter, Med: Informationsblätter, } \\
\text { Vereinszeitschrift); SHG in KR, } \\
\text { MG, NE, (andere Orte nach } \\
\text { Bedarf, Teilnahmedauer unbegr., } \\
\text { ohne therapeutische Leitung, max. } \\
\text { 10-12 Teilnehmer) }\end{array}$ & $\begin{array}{l}\text { allg. Info; Beratung durch Selbst- } \\
\text { betroffene, Fachleute u. Laien; } \\
\text { Interessenvertretung der Betroffe- } \\
\text { nen (Öff, Ver / Vor, Med); } \\
\text { bundesweit SHG (offene Gruppe, } \\
\text { ohne therapeutische bzw. minimale } \\
\text { therapeutische Leitung, } \\
\text { 5-25 Teilnehmer) }\end{array}$ \\
\hline Leitung & Vorstand & Prof. Dr. Gh. Sehhati-Chafai & Hiltrud Lisken (1. Vorsitzende) & $\begin{array}{l}\text { Dr. Marianne Koch (Präsidentin); } \\
\text { Rita Wanninger (Geschäftsstellen- } \\
\text { leiterin) }\end{array}$ \\
\hline Personal & k.A. & $\begin{array}{l}\text { Ingrid Kording } \\
\text { (Geschäftsführerin) }\end{array}$ & nur ehrenamtliche Mitarbeiter & ehrenamtliche Mitarbeiter \\
\hline Zusammenarbeit & $\begin{array}{l}\text { niedergelassene Therapeuten; } \\
\text { Fachkliniken; Krankenhäuser }\end{array}$ & $\begin{array}{l}\text { andere SHG; niedergelassene } \\
\text { Therapeuten; Fachkliniken; } \\
\text { Krankenhäuser; Ämter u. Behör- } \\
\text { den; sozialpsychiatrischer Dienst }\end{array}$ & $\begin{array}{l}\text { andere SHG u. SHO; ambulante } \\
\text { Beratungsstellen; niedergelassene } \\
\text { Therapeuten; Fachkliniken; } \\
\text { Krankenhäuser; Ämter u. Behör- } \\
\text { den; sozialpsychiatrischer Dienst }\end{array}$ & $\begin{array}{l}\text { Schmerztherapeutisches } \\
\text { Kolloquium e.V.; Deutsche } \\
\text { Rheumaliga e.V. }\end{array}$ \\
\hline Finanzierung & k.A & $\begin{array}{l}\text { öffentl. Zuschüsse; Mitglieds- } \\
\text { beiträge; Krankenkassen; } \\
\text { Kursgebühren }\end{array}$ & $\begin{array}{l}\text { Mitgliedsbeiträge; Krankenkassen } \\
\text { (Selbsthilfeförderung f. Projekte); } \\
\text { private Spenden; Kursgebühren }\end{array}$ & $\begin{array}{l}\text { Mitgliedsbeiträge; } \\
\text { private Spenden; Firmenspenden }\end{array}$ \\
\hline
\end{tabular}

allg. Info: allgemeine Informationen; begr.: begrenzt; div.: diverse; Fort: Fortbildung; k.A.: keine (näheren) Angaben; Kur: Kurse; Med: Medien; öffentl.: öffentlich; Öff: Öffentlichkeitsarbeit; Sem: Seminare; SH: Selbsthilfe; SHG: Selbsthilfegruppe(n); SHO: Selbsthilfeorganisation(en); Tag: Tagungen; unbegr.: unbegrenzt; Ver: Veranstaltungen; Vor: Vorträge; KR: Krefeld; MG: Mönchengladbach; NE: Neuss. 
Tab. 5b. Selbsthilfevereinigungen: Chronische Schmerzen II

\begin{tabular}{|c|c|c|}
\hline Organisation & MIGRÄNE LIGA e.V. & Vereinigung für chronische Schmerzpatienten (VSP) e.V. \\
\hline Adresse & $\begin{array}{l}\text { Nikolai Karheiding } \\
\text { Westerwaldstraße } 1 \\
65462 \text { Ginsheim-Gustavsburg } \\
\text { Tel. 06144-2211, Fax -31908 } \\
\text { karheiding@migraeneliga-deutschland.de } \\
\text { www.migraeneliga-deutschland.de (Migräne-Forum) }\end{array}$ & $\begin{array}{l}\text { Ingeborg Dittus } \\
\text { Nachtigallweg } 2 \\
75365 \text { Calw-Stammheim } \\
\text { Tel. } 07051 \text { 7-172, Fax }-7826\end{array}$ \\
\hline Kontaktaufnahme & telefonisch Mo-Fr 9:00-12:00 u. 14:00-16:00 Uhr & k.A. \\
\hline Zielgruppe & $\begin{array}{l}\text { Betroffene; Angehörige u. das gesamte Umfeld der Betroffenen (z.B. } \\
\text { Arbeitskollegen, Freunde u. a.); Therapeuten; Psychologen; Publizisten } \\
\text { und Journalisten }\end{array}$ & $\begin{array}{l}\text { chronisch Schmerzkranke u. deren Angehörige; professionelle Helfer; } \\
\text { Politiker; Öffentlichkeit }\end{array}$ \\
\hline Aufgaben & Austausch von Informationen u. Erfahrungen; Öffentlichkeitsarbeit & $\begin{array}{l}\text { Aufklärung u. Information; Beratung u. Unterstützung; } \\
\text { Öffentlichkeitsarbeit }\end{array}$ \\
\hline Angebote & $\begin{array}{l}\text { allg. Info; Beratung durch Fachleute; Interessenvertretung der } \\
\text { Betroffenen (Öff, Ver / Vor, Tag, Sem / Kur, Fort, Med: migräne } \\
\text { magazin); SHG (offene Gruppe, Teilnahmedauer unbegr., Ziele: Erler- } \\
\text { nen von Verhaltensmaßnahmen u. Akzeptieren der Erkrankung, ohne } \\
\text { therapeutische bzw. minimale therapeutische Leitung, Teilnehmerzahl } \\
\text { 10-25); Adressenliste von SHG im gesamten Bundesgebiet }\end{array}$ & $\begin{array}{l}\text { allg. Info; Beratung durch Selbstbetroffene u. Fachleute; Interessen- } \\
\text { vertretung der Betroffenen (Öff, Ver / Vor, Tag, Sem / Kur, Fort, Med); } \\
\text { Aktionsradius überregional, hängt von Aktivität der Mitglieder ab }\end{array}$ \\
\hline Leitung & $\begin{array}{l}\text { Nikolai Karheiding (Vorsitzender); Otto Uhl (Geschäftsführer); } \\
\text { Dr. Gerhard Fischer (Redaktion) }\end{array}$ & Ingeborg Dittus u. Roswitha Henne (Vorstand) \\
\hline Personal & ehrenamtliche Mitarbeiter & k.A. \\
\hline Zusammenarbeit & niedergelassene Therapeuten; Fachkliniken; Ämter u. Behörden & Experten; Krankenkassen u. a. Vereinigungen \\
\hline Finanzierung & Eigenmittel; Mitgliedsbeiträge; Krankenkassen; private Spenden & k.A. \\
\hline
\end{tabular}

allg. Info: allgemeine Informationen; begr.: begrenzt; div.: diverse; Fort: Fortbildung; k.A.: keine (näheren) Angaben; Kur: Kurse; Med: Medien; öffentl.: öffentlich; Öff: Öffentlichkeitsarbeit; Sem: Seminare; SH: Selbsthilfe; SHG: Selbsthilfegruppe(n); SHO: Selbsthilfeorganisation(en); Tag: Tagungen; unbegr.: unbegrenzt; Ver: Veranstaltungen; Vor: Vorträge.

Tab. 6. Selbsthilfevereinigungen: Erkrankungen des Bewegungsapparates

\begin{tabular}{|c|c|c|}
\hline Organisation & Deutsche Dystonie Gesellschaft (DDG) e.V. & Bundesverband Torticollis e.V. \\
\hline Adresse & $\begin{array}{l}\text { Frau Didi Jackson } \\
\text { Bockhorst } 45 \text { a } \\
\text { 22589 Hamburg } \\
\text { Tel.040 87-5602, Fax -082804 } \\
\text { Deutsche-Dystonie@t-online.de } \\
\text { www.dystonie.de }\end{array}$ & $\begin{array}{l}\text { Helga Weber } \\
\text { Eckernkamp } 39 \\
\text { 59077 Hamm } \\
\text { Tel.02389 53-6988, Fax -6289 } \\
\text { BVToriti@aol.com } \\
\text { www.BVTorticollis.de }\end{array}$ \\
\hline Zielgruppe & Betroffene; Ärzte; Kliniken; Medien u. Krankenkassen & Torticollis-Betroffene u. deren Angehörige; Ärzte u. Therapeuten \\
\hline Aufgaben & $\begin{array}{l}\text { Beratung u. Betreuung von Betroffenen u. deren Familien; Gründung } \\
\text { von regionalen SHG; Aufklärung über das Krankheitsbild; Förderung } \\
\text { von Forschungsprojekten }\end{array}$ & \\
\hline Angebote & $\begin{array}{l}\text { allg. Info; Beratung durch Selbstbetroffene; Interessenvertretung der } \\
\text { Betroffenen (Öff, Ver / Vor, Tag, Med: Broschüren, Informationsblatt } \\
\text { «Dystonie Aktuell»); regionale SHG (offene Gruppe, Teilnahmedauer } \\
\text { unbegr., minimale therapeutische Leitung); alle } 2 \text { J. Vergabe des } \\
\text { «Oppenheim-Preises» f. wiss. Arbeiten über Dystonie }\end{array}$ & $\begin{array}{l}\text { allg. Info; Interessenvertretung der Betroffenen (Öff, Ver / Vor, Tag: } \\
2 \text { Bundestreffen jährl., Med: Zeitschrift «Torticollis-Echo») }\end{array}$ \\
\hline Leitung & D. Jackson (Vorsitzende); H. Bahe (stellv. Vorsitzender) & Helga Weber (Vorsitzende); Hildegard Glang (stellv. Vorsitzende) \\
\hline Personal & 1 Schreibkraft (Teilzeit) & k.A. \\
\hline Zusammenarbeit & $\begin{array}{l}\text { Nationale Kontakt- und Informationsstelle zur Anregung und Unter- } \\
\text { stützung von SHG (NAKOS); Bundesarbeitsgemeinschaft «Hilfe für } \\
\text { Behinderte» (BAGH) e.V. }\end{array}$ & $\begin{array}{l}\text { Kontakte zu internationalen Torticollis-Vereinigungen } \\
\text { (z.B. NSTA National Spasmodicus Torticollis Association Inc., USA) }\end{array}$ \\
\hline Finanzierung & Mitgliedsbeiträge; private Spenden & Mitgliedsbeiträge; private Spenden \\
\hline
\end{tabular}

allg. Info: allgemeine Informationen; begr.: begrenzt; div.: diverse; Fort: Fortbildung; k.A.: keine (näheren) Angaben; Kur: Kurse; Med: Medien; öffentl.: öffentlich; Öff: Öffentlichkeitsarbeit; Sem: Seminare; SH: Selbsthilfe; SHG: Selbsthilfegruppe(n); SHO: Selbsthilfeorganisation(en); Tag: Tagungen; unbegr.: unbegrenzt; Ver: Veranstaltungen; Vor: Vorträge. 
Tab. 7a. Selbsthilfevereinigungen: Ess-Störungen I

\begin{tabular}{|c|c|c|c|c|}
\hline Organisation & $\begin{array}{l}\text { Beratungszentrum bei Ess-Störun- } \\
\text { gen DICK und DÜNN e.V. }\end{array}$ & $\begin{array}{l}\text { Waage e.V. Beratungsstelle für } \\
\text { Frauen mit Eßstörungen }\end{array}$ & $\begin{array}{l}\text { Overeaters Anonymous Interes- } \\
\text { sengemeinschaft (OA) e.V. }\end{array}$ & $\begin{array}{l}\text { Kabera e.V. Beratung und Be- } \\
\text { handlung bei EBstörungen }\end{array}$ \\
\hline Adresse & $\begin{array}{l}\text { Katharina Vogel } \\
\text { Innsbrucker Straße } 25 \\
\text { 10825 Berlin } \\
\text { Tel. 030-854-4994, Fax -8442 }\end{array}$ & $\begin{array}{l}\text { Frau Sturm } \\
\text { Eimsbütteler Straße } 53 \\
22769 \text { Hamburg } \\
\text { Tel. } 040 \text { 4-9149 41, } \\
\text { Fax -017 2733 }\end{array}$ & $\begin{array}{l}\text { Postfach } 106206 \\
\text { 28062 Bremen } \\
\text { Tel. } 04213272 \text { 24, } \\
\text { Fax } 02151779499\end{array}$ & $\begin{array}{l}\text { Bianca Bergstedt } \\
\text { Kurt-Schumacher-Straße } 2 \\
34117 \text { Kassel } \\
\text { Tel. 0561-7805 05, Fax -7102 } 27 \\
\text { kabera@t-online.de }\end{array}$ \\
\hline Kontaktaufnahme & $\begin{array}{l}\text { persönlich u. telefonisch Mo-Fr } \\
\text { 9:00-22:00 u. Sa 16:00-18:00 Uhr; } \\
\text { feste Beratungszeiten f. betroffene } \\
\text { Frauen, Jugendliche, Männer, } \\
\text { Eltern u. Angehörige sowie Fach- } \\
\text { kräfte aus dem psychosozialen } \\
\text { Bereich }\end{array}$ & $\begin{array}{l}\text { telefonisch Mo 10:00-13:00 u. Do } \\
\text { 15:00-17:00 Uhr; Einzelgespräche } \\
\text { außerhalb dieser Zeiten werden } \\
\text { telefonisch vereinbart }\end{array}$ & $\begin{array}{l}\text { telefonisch oder schriftlich; Liste f. } \\
\text { Anlaufstellen in D, A u. CH kann } \\
\text { unter der obigen Anschrift ange- } \\
\text { fordert werden }\end{array}$ & $\begin{array}{l}\text { telefonisch Mo 18:00-19:00, Di } \\
\text { 11:00-12:00, Mi 8:00-9:00 u. Do } \\
\text { 15:00-19:00 Uhr }\end{array}$ \\
\hline Zielgruppe & $\begin{array}{l}\text { essgestörte Erwachsene, Kinder } \\
\text { u. Jugendliche sowie deren } \\
\text { Angehörige }\end{array}$ & $\begin{array}{l}\text { Frauen, die Probleme mit dem } \\
\text { Essen haben; PartnerInnen, Eltern } \\
\text { von essgestörten Frauen u. } \\
\text { FreundInnen }\end{array}$ & Menschen mit Ess-Störungen & $\begin{array}{l}\text { essgestörte Frauen u. Männer } \\
\text { sowie deren Angehörige u.- } \\
\text { Freunde; MultiplikatorInnen }\end{array}$ \\
\hline Aufgaben & $\begin{array}{l}\text { Beratung u. Info f. Betroffene u. } \\
\text { Angehörige; Gründung, Anleitung } \\
\text { u. Betreuung von Selbsthilfe- } \\
\text { u. Langzeitgruppen; Prävention u. } \\
\text { Gesundheitsberatung; } \\
\text { Kooperation u. Vernetzung; } \\
\text { Fort- u. Weiterbildung }\end{array}$ & $\begin{array}{l}\text { Unterstützung von betroffenen } \\
\text { Frauen durch Beratungsgespräche } \\
\text { u. Gruppenangebote (z.B. SHG) }\end{array}$ & $\begin{array}{l}\text { Arbeit nach den } 12 \text { Schritten der } \\
\text { OA (in Anlehnung an die } \\
\text { Anonymen Alkoholiker); Erfah- } \\
\text { rung, Kraft u. Hoffnung teilen } \\
\text { sowie sich gegenseitig unterstützen }\end{array}$ & $\begin{array}{l}\text { Beratung u. Therapie sowie } \\
\text { Forschung, Fortbildung u. } \\
\text { Prävention; Bildungs- u. Öffent- } \\
\text { lichkeitsarbeit }\end{array}$ \\
\hline Angebote & $\begin{array}{l}\text { allg. Info; Beratung durch Fach- } \\
\text { leute; Interessenvertretung der } \\
\text { Betroffenen (Öff, Ver / Vor, Tag, } \\
\text { Sem / Kur, Fort, Med); } \\
\text { SHG f. Bulimikerinnen u. } \\
\text { Anorektikerinnen / } \\
\text { esssüchtige Frauen (geschlossene } \\
\text { Gruppe, Teilnahmedauer unbegr., } \\
\text { Ziele: gegenseitige Unterstützung, } \\
\text { Symptomreduzierung, minimale } \\
\text { therapeutische Leitung); SHG f. } \\
\text { Angehörige u. Essgestörte } \\
\text { (geschlossene Gruppe, Teilnahme- } \\
\text { dauer unbegr., Therapeuten-ange- } \\
\text { leitete Gruppe), SHG f. Jugend- } \\
\text { liche, Männer, Frauen ab } 35 \text { Lj. u. } \\
\text { lesbische Frauen }\end{array}$ & $\begin{array}{l}\text { allg. Info; Beratung durch Fach- } \\
\text { leute; Interessenvertretung der } \\
\text { Betroffenen (Öff, Ver / Vor, Tag, } \\
\text { Sem / Kur, Fort, Med); SHG } \\
\text { (f. Eltern von essgestörten Kindern, } \\
\text { f. Frauen mit Ess-Störungen u. f. } \\
\text { junge Frauen mit Ess-Störungen, } \\
\text { die bereits Klinik- oder Therapie- } \\
\text { erfahrung besitzen [18-22 J.], } \\
\text { geschlossene Gruppe, minimale } \\
\text { therapeutische Leitung aufgrund } \\
\text { von Anleitung); Gesprächsgrup- } \\
\text { pen; Nachsorge nach ambulanter } \\
\text { u. stationärer Therapie }\end{array}$ & $\begin{array}{l}\text { allg. Info; SHG f. Essgestörte in D, } \\
\text { A u. CH (offene Gruppe, Ziele: } \\
\text { Teilen von Erfahrung, Kraft u. } \\
\text { Hoffnung, um das gemeinsame } \\
\text { Problem des zwanghaften Essens } \\
\text { zu meistern, ohne therapeutische } \\
\text { Leitung) }\end{array}$ & $\begin{array}{l}\text { allg. Info; Beratung durch Fach- } \\
\text { leute; Interessenvertretung der } \\
\text { Betroffenen (Öff, Ver / Vor, Sem / } \\
\text { Kur, Fort, Med); SHG f. essgestörte } \\
\text { Männer u. Frauen / essgestörte } \\
\text { Frauen / Frauen mit emotional } \\
\text { bedingter Adipositas (Teilnahme- } \\
\text { dauer unbegr., minimale therapeu- } \\
\text { tische Leitung) }\end{array}$ \\
\hline Leitung & Dr. Almut Gemkow (Vorstand) & Vorstand & k.A. & k.A. \\
\hline Personal & $\begin{array}{l}2 \text { Dipl.-Psych.; } 3 \text { Soz.-Arb.; } \\
1 \text { Sekretärin }\end{array}$ & $\begin{array}{l}2 \text { Dipl.-Soz.-Päd.; } 1 \text { Dipl.-Päd. } \\
\text { (alle mit Zusatzausbildung) }\end{array}$ & k.A. & Dipl.-Päd.; Dipl.-Soz.-Päd. \\
\hline Zusammenarbeit & $\begin{array}{l}\text { andere SHG; ambulante Bera- } \\
\text { tungsstellen; niedergelassene } \\
\text { Therapeuten; Fachkliniken; } \\
\text { Krankenhäuser; Ämter u. } \\
\text { Behörden; sozialpsychiatrischer } \\
\text { Dienst }\end{array}$ & $\begin{array}{l}\text { KISS Hamburg u. KIBIS Lüne- } \\
\text { burg; ambulante Beratungsstellen; } \\
\text { niedergelassene Therapeuten; } \\
\text { Fachkliniken; Krankenhäuser; } \\
\text { Ämter u. Behörden; sozialpsychiat- } \\
\text { rischer Dienst; Ämter u. Behör- } \\
\text { den; Bundesfachverband Ess- } \\
\text { Störungen (BFE) e.V. }\end{array}$ & k. A. & Fachkliniken \\
\hline Finanzierung & $\begin{array}{l}\text { öffentl. Zuschüsse; Eigenmittel; } \\
\text { Mitgliedsbeiträge }\end{array}$ & öffentl. Zuschüsse & Eigenmittel & k.A. \\
\hline
\end{tabular}

allg. Info: allgemeine Informationen; begr.: begrenzt; div.: diverse; Fort: Fortbildung; k.A.: keine (näheren) Angaben; Kur: Kurse; Med: Medien; öffentl.: öffentlich; Öff: Öffentlichkeitsarbeit; Sem: Seminare; SH: Selbsthilfe; SHG: Selbsthilfegruppe(n); SHO: Selbsthilfeorganisation(en); Tag: Tagungen; unbegr.: unbegrenzt; Ver: Veranstaltungen; Vor: Vorträge. 
Tab. 7b. Selbsthilfevereinigungen: Ess-Störungen II

\begin{tabular}{|c|c|c|c|c|}
\hline Organisation & $\begin{array}{l}\text { Balance Beratung und Therapie } \\
\text { bei Ess-Störungen e.V. }\end{array}$ & $\begin{array}{l}\text { Frankfurter Zentrum für Ess- } \\
\text { Störungen (FZE) gGmbH }\end{array}$ & $\begin{array}{l}\text { Cinderella e.V. Aktionskreis } \\
\text { EB- und Magersucht }\end{array}$ & $\begin{array}{l}\text { ANAD e.V. Psychosoziale } \\
\text { Beratungsstelle für Eßstörungen }\end{array}$ \\
\hline Adresse & $\begin{array}{l}\text { Jutta Koletzki, Margit Küllmer } \\
\text { Waldschmidtstraße } 11 \\
\text { 60316 Frankfurt am Main } \\
\text { Tel.069 } 4908 \text { 63-30, Fax -31 } \\
\text { BALESS@t-online.de }\end{array}$ & $\begin{array}{l}\text { Marion Lindlar, } \\
\text { Andrea Speckhard } \\
\text { Hansaallee } 18 \\
60322 \text { Frankfurt } \\
\text { Tel. } 069 \text { 5-501 76, Fax -9617 } 23 \\
\text { fz.ess-stoerungen@t-online.de } \\
\text { www.fz-ess-stoerungen.de }\end{array}$ & $\begin{array}{l}\text { Ingrid Mieck, } \\
\text { Sabine Schoberth-Bernard } \\
\text { Westendstraße 35 } \\
80339 \text { München } \\
\text { Tel.089 502-1212, Fax -2575 } \\
\text { cinderellaberatg@aol.com } \\
\text { www.cinderella-rat-bei- } \\
\text { essstoerungen.de }\end{array}$ & $\begin{array}{l}\text { Frau Mergl, Frau Schüll, } \\
\text { Frau Grass-Oberemm } \\
\text { Seitzstraße } 8 \\
80538 \text { München } \\
\text { Tel.089 } 2423 \text { 99-60, Fax -66 } \\
\text { Kontakt@ANAD-pathways.de } \\
\text { www.ANAD-pathways.de }\end{array}$ \\
\hline Kontaktaufnahme & $\begin{array}{l}\text { wöchentlich wechselnde } \\
\text { telefonische Sprechzeiten } \\
\text { (mind. } 2 \text { h täglich) }\end{array}$ & $\begin{array}{l}\text { persönliche, telefonische oder } \\
\text { schriftliche Vereinbarung eines } \\
\text { Beratungstermins }\end{array}$ & $\begin{array}{l}\text { telefonisch Mo-Do 11:00-13:00 u. } \\
\text { 14:00-18:00 Uhr; Beratungsgesprä- } \\
\text { che erfordern die vorherige telefo- } \\
\text { nische Vereinbarung; an jedem } \\
\text { ersten Fr im Monat findet um 16:30 } \\
\text { Uhr ein offenes Beratungstreffen } \\
\text { statt }\end{array}$ & $\begin{array}{l}\text { telefonisch Mo-Do 10:00-18:00 u. } \\
\text { Fr 10:00 Uhr-17:00 Uhr }\end{array}$ \\
\hline Zielgruppe & $\begin{array}{l}\text { Kinder, Jugendliche, Frauen u. } \\
\text { Männer, die an Ess-Störungen } \\
\text { erkrankt sind; Menschen, die unter } \\
\text { ihrem Essverhalten oder anderen } \\
\text { seelisch bedingten Ess- oder } \\
\text { Appetitstörungen leiden; } \\
\text { Familienangehörige u. Partner }\end{array}$ & $\begin{array}{l}\text { Betroffene u. deren Angehörige; } \\
\text { Fachleute }\end{array}$ & $\begin{array}{l}\text { Menschen, die von Ess-Störungen } \\
\text { betroffen sind; Angehörige } \\
\text { u. Freunde; Multiplikatoren }\end{array}$ & $\begin{array}{l}\text { Betroffene; Angehörige } \\
\text { (Partner, Familie); Risikogruppen } \\
\text { (Prävention); Fachleute }\end{array}$ \\
\hline Aufgaben & $\begin{array}{l}\text { psychosoziale Beratung; Psycho- } \\
\text { therapie u. Behandlung; Gesund- } \\
\text { heitsförderung u. Fortbildung }\end{array}$ & $\begin{array}{l}\text { Beratung u. Therapie; Fortbildung } \\
\text { von Fachleuten }\end{array}$ & $\begin{array}{l}\text { Beratung bei Ess-Störungen; } \\
\text { Öffentlichkeitsarbeit; Vermittlung } \\
\text { von Kliniken; Therapeuten u. } \\
\text { Beratungsstellen in anderen } \\
\text { Städten }\end{array}$ & $\begin{array}{l}\text { psychosoziale Beratung bei } \\
\text { Ess-Störungen im Sinne der } \\
\text { Förderung bzw. Wiederherstellung } \\
\text { der psychischen u. körperlichen } \\
\text { Gesundheit; Prävention; } \\
\text { Aufklärungsarbeit }\end{array}$ \\
\hline Angebote & $\begin{array}{l}\text { allg. Info; Beratung durch } \\
\text { Fachleute; Interessenvertretung } \\
\text { der Betroffenen (Öff, Ver / Vor, } \\
\text { Sem / Kur, Fort); SHG (geschlos- } \\
\text { sene Gruppe, Teilnahmedauer } \\
\text { unbegr., minimale therapeutische } \\
\text { Leitung: 1-2 Anleitungstermine) }\end{array}$ & $\begin{array}{l}\text { Beratungsstelle: Einzelberatung f. } \\
\text { Betroffene u. Angehörige; Paar- u. } \\
\text { Familienberatung; Gruppen- / } \\
\text { Jugendgruppenberatung; Gruppen } \\
\text { f. essgestörte Mädchen; SHG f. } \\
\text { Frauen; Gruppen f. Angehörige; } \\
\text { Beantwortung von schriftlichen u. } \\
\text { telefonischen Anfragen regional u. } \\
\text { bundesweit; Arbeit mit } \\
\text { MultiplikatorInnen; Gründung u. } \\
\text { Anleitung von SHG; Informations- } \\
\text { abende zum Thema Ess-Störun- } \\
\text { gen, ihre Ursachen u. Behand- } \\
\text { lungsmöglichkeiten; Prävention u. }\end{array}$ & $\begin{array}{l}\text { allg. Info; Beratung durch Fach- } \\
\text { leute; Interessenvertretung der } \\
\text { Betroffenen (Öff, Ver / Vor, Fort, } \\
\text { Med); angeleitete SHG f. Frauen } \\
\text { mit verschiedenen Ess-Störungen } \\
\text { (20-35 J., unbegr. Teilnahmedauer) } \\
\text { u. (14-20 J., unbegr. Teilnahme- } \\
\text { dauer) sowie f. Frauen mit } \\
\text { Adipositas (Ende 20-Anfang } 60 \text { J., } \\
\text { unbegr. Teilnahmedauer); } \\
\text { Sonntagstreff f. Betroffene; «Jour } \\
\text { Fixe» f. ehemalige Betroffene; } \\
\text { Ernährungsberatung f. Betroffene }\end{array}$ & $\begin{array}{l}\text { Einzel-, Paar- u. Familiengespräche } \\
\text { f. Betroffene u. Angehörige; } \\
\text { Versand von Informationsmaterial } \\
\text { u. Adressenlisten von Beratungs- } \\
\text { stellen, niedergelassenen Thera- } \\
\text { peuten sowie Kliniken aus der } \\
\text { gesamten Bundesrepublik u. dem } \\
\text { deutschsprachigen Ausland, die im } \\
\text { Bereich «Ess-Störungen» tätig } \\
\text { sind; Essplanberatung f. Betrof- } \\
\text { fene; therapeutisch angeleitete } \\
\text { Gruppen f. Betroffene u. Eltern; } \\
\text { Elternseminare; Informationsver- } \\
\text { anstaltungen u. Weiterbildung }\end{array}$ \\
\hline
\end{tabular}

Gesundheitsförderung. Therapie-

bereich: Einzeltherapie / Einzelberatung; Gruppentherapie f. Frauen u. Männer. Fortbildungsbereich: Supervision $u$. Wochenendseminare f. Fachleute; Fortbildung f. Multiplikatoren; Fortbildungsreihen $\mathrm{f}$. Ernährungsfachleute

Leitung

Personal

Zusammenarbeit

Finanzierung
Jutta Koletzki, Margit Küllmer (Geschäftsführung)

Dipl.-Päd.; Dipl.-Soz.-Päd.; Dipl.-Psych.

andere SHG; Overeaters Anonymous e.V.; ambulante Beratungsstellen; niedergelassene Therapeuten; Fachkliniken; Krankenhäuser; Ämter u. Behörden; sozialpsychiatrischer Dienst; Bundesfachverband Ess-Störungen (BFE) e.V.

öffentl. Zuschüsse; Eigenmittel; private Spenden; Kursgebühren; Selbstzahler
Dr. phil. Barbara Krebs (Geschäftsführerin)

2 Beraterinnen u. 7 assozierte Therapeutinnen; 1 Koordinatorin; 1 Verwaltungskraft

ambulante Beratungsstellen; niedergelassene Therapeuten; Fachkliniken; Krankenhäuser; Ämter u. Behörden; sozialpsychiatrischer Dienst

öffentl. Mittel; Krankenkassen; private Spenden; Kursgebühren

\section{Eß- und Magersuch}

ssstoerungen.de

11:00-13:00 u. nische Vereinbarung; an jedem

Ess-Störungen en sind; Angehörige Öffentlichkeitsarbeit; Vermitt Kliniken; Therapeuten u. Beratungsstellen in anderen Med); angeleitete SHG f. Frauen Adipositas (Ende 20-Anfang $60 \mathrm{~J}$

Fixe» f. ehemalige Betroffene; anstaltungen $\mathrm{u}$. Weiterbildung

Vorstand: Dr. Silke Naab, Angelika Roß; Prof. Dr. M. Fichte

1 Dipl.-Psych.; 1 Dipl.-Soz.-Päd.

Bundesfachverband Ess-Störungen (BFE) e.V.; in München über den Münchener Arbeitskreis EssStörungen mit allen Einrichtungen, die Ess-Störungen zum Thema haben

öffentl. Zuschüsse; Mitgliedsbeiträge; private Spenden Einnahmen f. Beratungen
Dipl.-Soz.-Päd. (FH) Isabel Mergl

Dipl.-Psych.; Dipl.-Soz.-Päd.; Dipl.-Oecotroph.

Bundesfachverband Ess-Störungen; ambulante Beratungsstellen; niedergelassene Therapeuten;

Fachkliniken; Ämter u. Behörden

öffentl. Mittel; private Spenden; Eigenmittel

allg. Info: allgemeine Informationen; begr.: begrenzt; div.: diverse; Fort: Fortbildung; k.A.: keine (näheren) Angaben; Kur: Kurse; Med: Medien; öffentl.: öffentlich; Öff: Öffentlichkeitsarbeit; Sem: Seminare; SH: Selbsthilfe; SHG: Selbsthilfegruppe(n); SHO: Selbsthilfeorganisation(en); Tag: Tagungen; unbegr.: unbegrenzt; Ver: Veranstaltungen; Vor: Vorträge. 
Tab. 8. Selbsthilfevereinigungen: Gastrointestinale Erkrankungen und Inkontinenz

\begin{tabular}{|c|c|c|c|}
\hline Organisation & $\begin{array}{l}\text { CED-Hilfe Hamburg e.V. Hilfe bei Morbus Crohn } \\
\text { und Colitis ulcerosa }\end{array}$ & $\begin{array}{l}\text { Deutsche Morbus Crohn / Colitis ulcerosa } \\
\text { Vereinigung (DCCV) e.V. }\end{array}$ & GIH Gesellschaft für Inkontinenzhilfe e.V. \\
\hline Adresse & $\begin{array}{l}\text { Karin Voggesberger, Karin Herberger, } \\
\text { Ingrid Wiechelt } \\
\text { Fuhlsbüttler Straße } 401 \\
\text { 22309 Hamburg } \\
\text { Tel. u. Fax } 0406323740\end{array}$ & $\begin{array}{l}\text { Reinhard Schüren } \\
\text { Paracelsusstraße } 15 \\
51375 \text { Leverkusen } \\
\text { Tel. } 0214876 \text { 08-0, Fax -88 } \\
\text { info@dccv.de } \\
\text { www.dccv.de (Forum, Mailingliste u. Chat) }\end{array}$ & $\begin{array}{l}\text { Friedrich-Ebert-Straße } 124 \\
34119 \text { Kassel } \\
\text { Tel. 0561-7806 04, Fax -7767 } 70 \\
\text { GIH-Kassel@t-online.de } \\
\text { www.gih.de }\end{array}$ \\
\hline Kontaktaufnahme & $\begin{array}{l}\text { persönlich u. telefonisch Mo, } \\
\text { Di u. Do 10:00-13:00 Uhr }\end{array}$ & $\begin{array}{l}\text { persönlich Mo-Fr 9:00-12:00 u. } \\
\text { 12:30-17:00 Uhr; telefonisch Mo } \\
\text { 9:00-12:00 u. Di-Do 14:00-17:00 Uhr }\end{array}$ & k.A. \\
\hline Zielgruppe & Menschen mit Morbus Crohn u. Colitis ulcerosa & $\begin{array}{l}\text { Menschen, die an Morbus Crohn o. Colitis } \\
\text { ulcerosa erkrankt sind u. deren Angehörige }\end{array}$ & Menschen mit Harn- u. Stuhlinkontinenz \\
\hline Aufgaben & $\begin{array}{l}\text { Information u. Beratung } \\
\text { (auch Ernährungsberatung); Förderung von SH }\end{array}$ & $\begin{array}{l}\text { Bemühung um eine Erweiterung u. Ver- } \\
\text { besserung der ambulanten u. klinischen } \\
\text { Versorgung; Information u. Öffentlich- } \\
\text { keitsarbeit; Interessenvertretung }\end{array}$ & $\begin{array}{l}\text { Förderung von Maßnahmen zur Präven- } \\
\text { tion, Diagnostik, Behandlung u. Versor- } \\
\text { gung der Harn- u. Stuhlinkontinenz }\end{array}$ \\
\hline Angebote & $\begin{array}{l}\text { allg. Info; Beratung durch Selbstbetroffene; } \\
\text { Interessenvertretung der Betroffenen (Öff, Ver / } \\
\text { Vor, Tag, Sem / Kur, Med: Infomaterial, Patienten- } \\
\text { zeitschrift); SHG (Gruppe in Form eines «offenen } \\
\text { Abends» mit wechselnden Teilnehmern, Teilnahme- } \\
\text { dauer unbegr., ohne therapeutische Leitung) }\end{array}$ & $\begin{array}{l}\text { allg. Info; Beratung durch Selbstbetroffene } \\
\text { u. Fachleute; Interessenvertretung der } \\
\text { Betroffenen (Öff, Ver / Vor, Tag, Sem / } \\
\text { Kur, Fort, Med: Mitgliederjournal «Bauch- } \\
\text { redner»); regionale SHG (offene Gruppe, } \\
\text { Teilnahmedauer unbegr., Ziele: Erfah- } \\
\text { rungsaustausch, gegenseitige Unterstüt- } \\
\text { zung u. Beratung, selbst organisierte Fort- } \\
\text { bildung; ohne therapeutische Leitung / } \\
\text { Therapeuten-angeleitete Gruppe) }\end{array}$ & $\begin{array}{l}\text { allg. Info; Interessenvertretung der Betrof- } \\
\text { fenen; bundesweit SHG }\end{array}$ \\
\hline Leitung & $\begin{array}{l}\text { Karin Voggesberger, Karin Herberger, } \\
\text { Ingrid Wiechelt (Vorstand) }\end{array}$ & ehrenamtlicher Vorstand & $\begin{array}{l}\text { Prof. Dr. Hansjörg Melchior } \\
\text { (1. Vorsitzender); } \\
\text { Prof. Dr. Ingo Füsgen (2. Vorsitzender) }\end{array}$ \\
\hline Personal & k.A. & Fachleute (Ärzte, Psychotherapeuten u. a.) & k.A. \\
\hline Zusammenarbeit & $\begin{array}{l}\text { Deutsche ILCO; Deutsche Morbus Crohn / Colitis } \\
\text { ulcerosa Vereinigung (DCCV) e.V.; ambulante } \\
\text { Beratungsstellen; niedergelassene Therapeuten; } \\
\text { Krankenhäuser }\end{array}$ & $\begin{array}{l}\text { ambulante Beratungsstellen; nieder- } \\
\text { gelassene Therapeuten; Fachkliniken; } \\
\text { Krankenhäuser; Ämter u. Behörden; } \\
\text { sozialpsychiatrischer Dienst }\end{array}$ & $\begin{array}{l}\text { Fachkliniken, niedergelassene } \\
\text { Therapeuten, Ämter u. Behörden }\end{array}$ \\
\hline Finanzierung & Mitgliedsbeiträge; private Spenden & $\begin{array}{l}\text { öffentl. Zuschüsse; Eigenmittel; } \\
\text { Mitgliedsbeiträge; Krankenkassen; private } \\
\text { Spenden; Kursgebühren }\end{array}$ & $\begin{array}{l}\text { öffentl. Zuschüsse; Eigenmittel; } \\
\text { Mitgliedsbeiträge, Krankenkassen; } \\
\text { private Spenden; Kursgebühren }\end{array}$ \\
\hline
\end{tabular}

allg. Info: allgemeine Informationen; begr.: begrenzt; div.: diverse; Fort: Fortbildung; k.A.: keine (näheren) Angaben; Kur: Kurse; Med: Medien; öffentl.: öffentlich; Öff: Öffentlichkeitsarbeit; Sem: Seminare; SH: Selbsthilfe; SHG: Selbsthilfegruppe(n); SHO: Selbsthilfeorganisation(en); Tag: Tagungen; unbegr.: unbegrenzt; Ver: Veranstaltungen; Vor: Vorträge. 
Tab. 9. Selbsthilfevereinigungen: Hauterkrankungen

\begin{tabular}{|c|c|c|c|c|}
\hline Organisation & $\begin{array}{l}\text { Deutscher Neurodermitiker Bund } \\
\text { (DNB) e.V. }\end{array}$ & $\begin{array}{l}\text { Deutscher Psoriasis Bund (DPB) } \\
\text { e.V. Selbsthilfe bei Schuppen- } \\
\text { flechte }\end{array}$ & $\begin{array}{l}\text { Bundesverband Neurodermitis- } \\
\text { kranker in Deutschland e.V. }\end{array}$ & Haut-Selbsthilfe e.V. \\
\hline Adresse & $\begin{array}{l}\text { Elke Zimmer, Dorothea Schlotte } \\
\text { Spaldingstraße } 210 \\
20097 \text { Hamburg } \\
\text { Tel. } 040 \text { 23-0180, Fax -1008 } \\
\text { info@dnb-ev.de } \\
\text { www.dnb-ev.de }\end{array}$ & $\begin{array}{l}\text { - Geschäftsstelle - } \\
\text { Oberaltenallee 20 a } \\
\text { 22081 Hamburg } \\
\text { Tel.040 } 2233 \text { 99-0, Fax -22 } \\
\text { DPB.Hamburg@t-online.de } \\
\text { www.psoriasis.bund.de }\end{array}$ & $\begin{array}{l}\text { Jürgen Pfeifer } \\
\text { Oberstraße } 171 \\
\text { Postfach } 1165 \\
\text { 56154 Boppard } \\
\text { Tel. 06742-871 30, Fax -2795 } \\
\text { Bvneuro@aol.com } \\
\text { info@neurodermitis.net } \\
\text { www.neurodermitis.net }\end{array}$ & $\begin{array}{l}\text { Gisela Bellmann } \\
\text { Augrät } 14 \\
66809 \text { Nalbach } \\
\text { Tel. u. Fax } 068386282\end{array}$ \\
\hline Kontaktaufnahme & $\begin{array}{l}\text { persönlich u. telefonisch } \\
\text { Mo-Do 10:00-12:00 u. 15:00-17:00; } \\
\text { Fr 10:00-12:00 u. 13:30-15:30 Uhr }\end{array}$ & telefonisch Mo-Fr 9:00-16:00 Uhr & $\begin{array}{l}\text { persönlich u. telefonisch } \\
\text { Mo-Fr 7:30-12:00 } \\
\text { u. Mo-Do 13:00-16:30 Uhr }\end{array}$ & $\begin{array}{l}\text { persönlich u. telefonisch } \\
\text { Mo-So 8:00-22:00 Uhr }\end{array}$ \\
\hline Zielgruppe & $\begin{array}{l}\text { Neurodermitis-Patienten u. deren } \\
\text { Angehörige }\end{array}$ & $\begin{array}{l}\text { Menschen mit Psoriasis } \\
\text { u. Öffentlichkeit }\end{array}$ & $\begin{array}{l}\text { Menschen mit Neurodermitis, } \\
\text { Asthma, Allergien, Psoriasis u. a. }\end{array}$ & $\begin{array}{l}\text { Menschen mit chronischen } \\
\text { u. akuten Hauterkrankungen }\end{array}$ \\
\hline Aufgaben & $\begin{array}{l}\text { Sammlung u. Vermittlung von In- } \\
\text { formationen; Interessenvertretung; } \\
\text { Beratung von Patienten u. deren } \\
\text { Angehörigen; Bildung u. Unterhal- } \\
\text { tung von SHG }\end{array}$ & $\begin{array}{l}\text { Verbesserung der Versorgung; } \\
\text { Aufklärung der Öffentlichkeit; } \\
\text { Förderung der Forschung; natio- } \\
\text { nale u. internationale Zusammen- } \\
\text { arbeit mit anderen SHO }\end{array}$ & $\begin{array}{l}\text { Information; Beratung; Hilfe zur } \\
\text { SH; Öffentlichkeitsarbeit }\end{array}$ & $\begin{array}{l}\text { Aufklärung u. Information; } \\
\text { Beratung; Hilfe u. Unterstützung }\end{array}$ \\
\hline Angebote & $\begin{array}{l}\text { allg. Info; Beratung durch } \\
\text { Selbstbetroffene u. Fachleute; } \\
\text { Interessenvertretung der Betrof- } \\
\text { fenen (Öff, Ver / Vor, Med: } \\
\text { Mitgliederzeitschrift «Hautfreund» } \\
6 \times \text { jährl.); bundesweit etwa } \\
30 \text { SHG u. } 120 \text { ehrenamtliche } \\
\text { Ansprechpartner }\end{array}$ & $\begin{array}{l}\text { allg. Info; Beratung durch Selbst- } \\
\text { betroffene u. Fachleute; Interes- } \\
\text { senvertretung der Betroffenen } \\
\text { (Öff, Ver / Vor, Tag, Sem / Kur, } \\
\text { Fort, Med: «PSO Magazin»); SHG } \\
\text { (offene Gruppe, Teilnahmedauer } \\
\text { unbegr., ohne therapeutische } \\
\text { Leitung); bundesweit Regional- } \\
\text { gruppen }\end{array}$ & $\begin{array}{l}\text { allg. Info; Beratung durch Selbst- } \\
\text { betroffene u. Laien; Interessenver- } \\
\text { tretung der Betroffenen (Öff, Ver / } \\
\text { Vor, Tag, Sem / Kur, Fort, Med: } \\
\text { Zeitschrift «Neurodermitis», } \\
\text { Broschüren, Videofilme); bundes- } \\
\text { weit etwa } 65 \text { SHG (offene Gruppe, } \\
\text { Teilnahmedauer unbegr., ohne } \\
\text { therapeutische Leitung) }\end{array}$ & $\begin{array}{l}\text { allg. Info; Beratung durch Selbst- } \\
\text { betroffene, Fachleute u. Laien; } \\
\text { Interessenvertretung der Betrof- } \\
\text { fenen (Öff, Ver / Vor, Tag, Sem / } \\
\text { Kur, Fort, Med); SHG (offene } \\
\text { Gruppe, Teilnahmedauer unbegr., } \\
\text { ohne therapeutische Leitung); } \\
\text { bundesweite Gründung von SHG } \\
\text { in Planung }\end{array}$ \\
\hline Leitung & $\begin{array}{l}\text { Thomas Schwennesen (1. Vorsit- } \\
\text { zender u. Geschäftsführer) }\end{array}$ & $\begin{array}{l}\text { PD Dr. Ekkehard W. Jecht } \\
\text { (Vorsitzender) }\end{array}$ & $\begin{array}{l}\text { Jürgen Pfeifer (Vorsitzender u. } \\
\text { Bundesgeschäftsführer) }\end{array}$ & $\begin{array}{l}\text { Gisela Bellmann (1. Vorsitzende); } \\
\text { Edmund Allard (2. Vorsitzender) }\end{array}$ \\
\hline Personal & 1 Dipl.-Soz.; 1 Dipl.-Oecotroph. & $\begin{array}{l}\text { Fachleute u. ehrenamtliche } \\
\text { Mitarbeiter }\end{array}$ & $\begin{array}{l}\text { Bürofachkräfte; ehrenamtliche } \\
\text { Mitarbeiter }\end{array}$ & verschiedene Mitarbeiter \\
\hline Zusammenarbeit & k.A. & $\begin{array}{l}\text { niedergelassene Therapeuten; } \\
\text { Fachkliniken; Krankenhäuser; } \\
\text { Ämter u. Behörden; } \\
\text { sozialpsychiatrischer Dienst }\end{array}$ & $\begin{array}{l}\text { ambulante Beratungsstellen; } \\
\text { niedergelassene Therapeuten; } \\
\text { Fachkliniken; Krankenhäuser }\end{array}$ & $\begin{array}{l}\text { ambulante Beratungsstellen; } \\
\text { niedergelassene Therapeuten; } \\
\text { Fachkliniken; Krankenhäuser; } \\
\text { Ämter u. Behörden; } \\
\text { sozialpsychiatrischer Dienst }\end{array}$ \\
\hline Finanzierung & $\begin{array}{l}\text { Mitgliedsbeiträge; Krankenkassen; } \\
\text { private Spenden }\end{array}$ & $\begin{array}{l}\text { öffentl. Zuschüsse; Eigenmittel; } \\
\text { Mitgliedsbeiträge; Krankenkassen; } \\
\text { private Spenden; Kursgebühren }\end{array}$ & $\begin{array}{l}\text { Mitgliedsbeiträge; Krankenkassen; } \\
\text { private Spenden }\end{array}$ & $\begin{array}{l}\text { öffentl. Zuschüsse; Eigenmittel; } \\
\text { Mitgliedsbeiträge; Krankenkassen } \\
\text { private Spenden; Kursgebühren }\end{array}$ \\
\hline
\end{tabular}

allg. Info: allgemeine Informationen; begr.: begrenzt; div.: diverse; Fort: Fortbildung; k.A.: keine (näheren) Angaben; Kur: Kurse; Med: Medien; öffentl.: öffentlich; Öff: Öffentlichkeitsarbeit; Sem: Seminare; SH: Selbsthilfe; SHG: Selbsthilfegruppe(n); SHO: Selbsthilfeorganisation(en); Tag: Tagungen; unbegr.: unbegrenzt; Ver: Veranstaltungen; Vor: Vorträge. 
Tab. 10. Selbsthilfevereinigungen: Hör- und Sprachbehinderungen

\begin{tabular}{|c|c|c|}
\hline Organisation & Deutsche Tinnitus-Liga (DTL) e.V. & Bundesvereinigung Stotterer-Selbsthilfe e.V. \\
\hline Adresse & $\begin{array}{l}\text { Sybille Heil } \\
\text { Am Lohsiepen } 18 \\
42369 \text { Wuppertal } \\
\text { Tel. 0202 2465-20, Fax -220 } \\
\text { dtl@tinnitus-liga.de } \\
\text { www.tinnitus-liga.de }\end{array}$ & $\begin{array}{l}\text { Ruth E. Heap } \\
\text { Gereonswall } 112 \\
\text { 50670 Köln } \\
\text { Tel. } 0221 \text { 139-1106 o. - 1107, Fax -1370 } \\
\text { stotterbv@t-online.de } \\
\text { www.bvss.de (Mailingliste) }\end{array}$ \\
\hline Kontaktaufnahme & telefonisch Mo-Do 9:00-12:00 u. 14:00-16:00; Fr 9:00-12:00 Uhr & $\begin{array}{l}\text { telefonisch Mo u. Di 9:00-17:30, Mi 12:00-20:00, Do 9:00-20:00 } \\
\text { u. Fr 9:00-15:00 Uhr }\end{array}$ \\
\hline Zielgruppe & $\begin{array}{l}\text { Tinnitus-, Hörsturz- u. Morbus Menière-Betroffene sowie deren } \\
\text { Angehörige }\end{array}$ & $\begin{array}{l}\text { Betroffene; Eltern stotternder Kinder; Therapeuten; Erzieher; Lehrer } \\
\text { u. Ärzte }\end{array}$ \\
\hline Aufgaben & $\begin{array}{l}\text { Wahrung u. Förderung der gesundheitlichen, sozialen u. sozialrecht- } \\
\text { lichen Interessen der Betroffenen sowie deren Angehörigen; } \\
\text { Krankheitsverhütung; Vermittlung von Möglichkeiten zur SH; } \\
\text { Verbesserung von Forschung u. Lehre sowie der Selbsthilfe- u. } \\
\text { Beratungsmöglichkeiten }\end{array}$ & Information u. Beratung; Fort- u. Weiterbildung \\
\hline Angebote & $\begin{array}{l}\text { Beratung durch Selbstbetroffene, Fachleute u. Laien; Interessenvertre- } \\
\text { tung der Betroffenen (Öff, Ver / Vor, Tag, Sem / Kur, Med: Zeitschrift } \\
\text { «Tinnitus-Forum» } 4 \times \text { jährl.); bundesweit SHG f. Tinnitus u. Morbus } \\
\text { Menière-Betroffene }\end{array}$ & $\begin{array}{l}\text { allg. Info; Beratung durch Fachleute u. Selbstbetroffene; Interessen- } \\
\text { vertretung der Betroffenen (Öff, Ver / Vor, Tag, Sem / Kur, Fort, Med: } \\
\text { Zeitschrift «Der Kieselstein», Bücher, Ratgeber, Videofilme); bundes- } \\
\text { weit SHG f. stotternde Erwachsene u. Jugendliche ( } 3-15 \text { Teilnehmer) }\end{array}$ \\
\hline Leitung & Elke Knör (Vorsitzende u. Geschäftsführerin) & Ruth E. Heap (Geschäftsführerin) \\
\hline Personal & k.A. & k.A. \\
\hline Zusammenarbeit & $\begin{array}{l}\text { Deutscher Schwerhörigenbund; ambulante Beratungsstellen; } \\
\text { niedergelassene Therapeuten; Fachkliniken; Krankenhäuser; Ämter u. } \\
\text { Behörden; sozialpsychiatrischer Dienst }\end{array}$ & $\begin{array}{l}\text { andere SHO; ambulante Beratungsstellen; niedergelassene } \\
\text { Therapeuten; Fachkliniken; Ämter u. Behörden }\end{array}$ \\
\hline Finanzierung & öffentl. Zuschüsse; Mitgliedsbeiträge; Krankenkassen; private Spenden & $\begin{array}{l}\text { öffentl. Zuschüsse; Eigenmittel; Mitgliedsbeiträge; Krankenkassen; } \\
\text { private Spenden; Kursgebühren; Verkauf von Büchern u. Videofilmen }\end{array}$ \\
\hline
\end{tabular}

allg. Info: allgemeine Informationen; begr.: begrenzt; div.: diverse; Fort: Fortbildung; k.A.: keine (näheren) Angaben; Kur: Kurse; Med: Medien; öffentl.: öffentlich; Öff: Öffentlichkeitsarbeit; Sem: Seminare; SH: Selbsthilfe; SHG: Selbsthilfegruppe(n); SHO: Selbsthilfeorganisation(en); Tag: Tagungen; unbegr.: unbegrenzt; Ver: Veranstaltungen; Vor: Vorträge.

Tab. 11. Selbsthilfevereinigungen: Lebenskrisen

\begin{tabular}{|c|c|c|}
\hline Organisation & TABU e.V., Trauer- und Lebensberatungsstelle & Trauer Wege e.V. \\
\hline Adresse & $\begin{array}{l}\text { Dirk Matzik, Christina Kudling } \\
\text { Tiegelstraße } 23 \\
45141 \text { Essen } \\
\text { Tel. 020132-8777, Fax -5368 } \\
\text { tabu-team@online.de } \\
\text { www.tabu-team.de }\end{array}$ & $\begin{array}{l}\text { Petra Theumer (Beratung) } \\
\text { Petra Hugo (Fachberatung, Aus- u. Weiterbildung) } \\
\text { Breite Straße } 21 \\
55124 \text { Mainz } \\
\text { Tel. 06131-2311 00, Fax -4674 } 92\end{array}$ \\
\hline Kontaktaufnahme & persönlich nach Absprache; telefonisch Mo-Fr 9:30-18:00 Uhr. & $\begin{array}{l}\text { persönlicher Kontakt nach Terminabsprache; telefonisch Mo u. Do } \\
\text { 9:00-12:00 Uhr }\end{array}$ \\
\hline Zielgruppe & $\begin{array}{l}\text { Menschen in Trauer (durch Verlusterlebnisse); Interessierte (Ärzte, } \\
\text { Psychologen, Seelsorger) }\end{array}$ & $\begin{array}{l}\text { Menschen in Verlust-, Mangel-, Umbruch- u. Krisensituationen; beruf- } \\
\text { lich Betroffene u. Interessierte }\end{array}$ \\
\hline Aufgaben & $\begin{array}{l}\text { Begleitung von Menschen in Verlust- u. Abschiedssituationen; Aus- u. } \\
\text { Fortbildung von Mitarbeitern aus Berufsgruppen, die mit der Realität } \\
\text { von Sterben u. Tod konfrontiert sind }\end{array}$ & $\begin{array}{l}\text { Beratung u. Begleitung (einzeln u. Gruppen); Aus- u. Fortbildung; Auf- } \\
\text { klärung u. Information; Vernetzung mit verwandten Organisationen }\end{array}$ \\
\hline Angebote & $\begin{array}{l}\text { allg. Info; Beratung durch Selbstbetroffene u. Fachleute; Interessenver- } \\
\text { tretung der Betroffenen (Öff, Ver / Vor, Sem / Kur, Med); bundesweit } \\
\text { SHG (offene Gruppe, Teilnahmedauer unbegr., Ziele: Erfahrungsaus- } \\
\text { tausch u. Unterstützung, ausgebildete Trauerbegleiterinnen); «Kontakt- } \\
\text { Café» Mi 16:15-18:00 Uhr (Anschrift s.o.) }\end{array}$ & $\begin{array}{l}\text { allg. Info; Beratung durch Selbstbetroffene u. Fachleute; Interessen- } \\
\text { vertretung der Betroffenen (Öff, Ver / Vor, Tag, Sem / Kur, Fort, Med); } \\
\text { SHG (offene Gruppe, Teilnahmedauer unbegr., ohne therapeutische } \\
\text { Leitung, Anzahl der Teilnehmer variabel); SHG (geschlossene Gruppe, } \\
\text { Teilnahmedauer unbegr., Ziel: Entfaltung trostvoller Kräfte in der } \\
\text { Gruppe, minimale therapeutische Leitung, 7-9 Teilnehmer) }\end{array}$ \\
\hline Leitung & k.A. & Petra Hugo u. Petra Theumer \\
\hline Personal & k.A. & Petra Hugo u. Petra Theumer; 1 Sekretärin \\
\hline Zusammenarbeit & $\begin{array}{l}\text { kooperiert mit anderen Institutionen und ausgebildeten Fachkräften, } \\
\text { wie Ärzten, Psych., Seelsorgern u. Päd. }\end{array}$ & $\begin{array}{l}\text { Hospizgesellschaft «Christophorus e.V.» Mainz; «Trauernde Eltern» } \\
\text { Main e.V.; Krankenhäuser; Ämter u. Behörden }\end{array}$ \\
\hline Finanzierung & k.A & öffentl. Zuschüsse; Mitgliedsbeiträge; private Spenden; Kursgebühren \\
\hline
\end{tabular}

allg. Info: allgemeine Informationen; begr.: begrenzt; div.: diverse; Fort: Fortbildung; k.A.: keine (näheren) Angaben; Kur: Kurse; Med: Medien; öffentl.: öffentlich; Öff: Öffentlichkeitsarbeit; Sem: Seminare; SH: Selbsthilfe; SHG: Selbsthilfegruppe(n); SHO: Selbsthilfeorganisation(en); Tag: Tagungen; unbegr.: unbegrenzt; Ver: Veranstaltungen; Vor: Vorträge. 
Tab. 12. Selbsthilfevereinigungen: Neurologische Erkrankungen / Behinderungen I

\begin{tabular}{|c|c|c|c|c|}
\hline Organisation & $\begin{array}{l}\text { Deutsche Epilepsievereinigung } \\
\text { (DE) gem. e.V. }\end{array}$ & $\begin{array}{l}\text { Schritt für Schritt, Hilfe für das } \\
\text { hirnverletzte Kind e.V. }\end{array}$ & $\begin{array}{l}\text { Tourette-Gesellschaft Deutschland } \\
\text { (TGD) e.V. }\end{array}$ & $\begin{array}{l}\text { Informationszentrum Epilepsie } \\
\text { (IZE) e.V. }\end{array}$ \\
\hline Adresse & $\begin{array}{l}\text { Robert Bauer } \\
\text { Zillestraße } 102 \\
10585 \text { Berlin } \\
\text { Tel. } 030342 \text { 44-14, Fax -66 } \\
\text { info@epilepsie.sh } \\
\text { www.epilepsie.sh } \\
\text { (Disskussionsforum; Chat) }\end{array}$ & $\begin{array}{l}\text { Institut f. ganzheitliche } \\
\text { Kindesentwicklung gGmbH } \\
\text { Bernhard Jürs, Wolfgang Vogt } \\
\text { Alsterstraße } 2 \\
20354 \text { Hamburg } \\
\text { Tel. } 040447262 \\
\text { s.f.s.@t-online.de } \\
\text { www.schritt-fuer-schritt.de }\end{array}$ & $\begin{array}{l}\text { Karl Joseph } \\
\text { Stöltinghof } 1 \\
30445 \text { Hannover } \\
\text { Fax } 0511486262 \\
\text { info@tourette.de } \\
\text { (Christian Hempel) } \\
\text { www.tourette.de }\end{array}$ & $\begin{array}{l}\text { Petra Gehle, Beate Kröger } \\
\text { Herforder Straße 5-7 } \\
33602 \text { Bielefeld } \\
\text { Tel. 0521 1241-17, Fax -72 } \\
\text { ize@izepilepsie.de } \\
\text { www.izepilepsie.de }\end{array}$ \\
\hline Kontaktaufnahme & $\begin{array}{l}\text { persönlich u. telefonisch } \\
\text { Mo-Do 10:00-16:00 Uhr }\end{array}$ & $\begin{array}{l}\text { persönlich u. telefonisch Mo-Fr } \\
\text { 8:00-16:30 Uhr }\end{array}$ & telefonisch Mo-So 9:00-21:00 Uhr & $\begin{array}{l}\text { persönlich u. telefonisch Mo-Fr } \\
\text { 9:00-12:00 Uhr; Termine außerhalb } \\
\text { der Sprechzeiten möglich }\end{array}$ \\
\hline Zielgruppe & $\begin{array}{l}\text { Menschen mit Epilepsie u. deren } \\
\text { Angehörige; Interessierte }\end{array}$ & $\begin{array}{l}\text { Kinder mit Zerebralparese } \\
\text { (Spastik, Athetose, Ataxie) }\end{array}$ & $\begin{array}{l}\text { Eltern von jungen Patienten; } \\
\text { Ärzte; Neurologen; Psychothera- } \\
\text { peuten; Lehrer u. soziale Einrich- } \\
\text { tungen }\end{array}$ & $\begin{array}{l}\text { Menschen mit Epilepsie u. deren } \\
\text { Angehörige; Pflegepersonal; Ärzte } \\
\text { u. Interessierte }\end{array}$ \\
\hline Aufgaben & $\begin{array}{l}\text { Information; Beratung; Fortbil- } \\
\text { dung; Vernetzung u. Koordination }\end{array}$ & $\begin{array}{l}\text { Beratung u. Förderung der } \\
\text { Kompetenz von Eltern; früheste } \\
\text { Förderung der Kinder }\end{array}$ & $\begin{array}{l}\text { Vermittlung von Fachärzten; } \\
\text { Öffentlichkeitsarbeit; Aufklärung; } \\
\text { Förderung der wiss. Forschung u. } \\
\text { Behandlungsmethoden }\end{array}$ & $\begin{array}{l}\text { Information; Beratung; } \\
\text { Aufklärung }\end{array}$ \\
\hline Angebote & $\begin{array}{l}\text { allg. Info; Beratung durch Selbst- } \\
\text { betroffene u. Fachleute; Interes- } \\
\text { senvertretung der Betroffenen } \\
\text { (Öff, Ver / Vor, Tag, Sem / Kur, } \\
\text { Fort, Med: Zeitschrift «Einfälle»); } \\
\text { bundesweit etwa 250 SHG } \\
\text { u. Kontaktstellen }\end{array}$ & $\begin{array}{l}\text { allg. Info; Beratung durch betroffe- } \\
\text { ne Eltern u. Fachleute; Interessen- } \\
\text { vertretung der Betroffenen (Öff, } \\
\text { Ver / Vor, Tag, Sem / Kur, Fort); } \\
\text { SHG f. Eltern von hirnverletzten } \\
\text { bzw. behinderten Kindern (offene } \\
\text { Gruppe, Teilnahmedauer unbegr., } \\
\text { Ziele: Erfahrungs- u. Informa- } \\
\text { tionsaustausch, ohne therapeuti- } \\
\text { sche Leitung, Teilnehmerzahl } \\
\text { 5-70) }\end{array}$ & $\begin{array}{l}\text { allg. Info; Beratung durch Selbst- } \\
\text { betroffene, Fachleute u. Eltern; } \\
\text { Interessenvertretung der Betroffe- } \\
\text { nen (Öff, Ver / Vor, Tag, Med); } \\
\text { SHG Niedersachsen in H (offene } \\
\text { Gruppe, Teilnahmedauer unbegr., } \\
\text { Gruppenziel: Besprechung der } \\
\text { gemeinsamen Probleme, Thera- } \\
\text { peuten-angeleitete Gruppe, etwa } \\
30 \text { Teilnehmer); weitere SHG in B, } \\
\text { F, HF, HH, K, KA, M, MA, N, OS, } \\
\text { S u. SB }\end{array}$ & $\begin{array}{l}\text { allg. Info (Vermittlung von } \\
\text { Kontakten zu Fachleuten); } \\
\text { Beratung durch Fachleute u. Laien }\end{array}$ \\
\hline Leitung & $\begin{array}{l}\text { Robert Bauer } \\
\text { (Geschäftsstellenleiter) }\end{array}$ & $\begin{array}{l}\text { Bernhard Jürs (Vorsitzender des } \\
\text { Vereins); Wolfgang Vogt } \\
\text { (Geschäftsführer des Instituts) }\end{array}$ & Karl Joseph (1. Vorsitzender) & Prof. Dr. H.-J. Schwager \\
\hline Personal & $\begin{array}{l}\text { Mitarbeiter mit Hochschul- } \\
\text { abschluss u. ehrenamtliche } \\
\text { Mitarbeiter }\end{array}$ & Fachleute; 1 Zivildienstleistender & 1 Sekretärin & 2 kaufmännische Angestellte \\
\hline Zusammenarbeit & $\begin{array}{l}\text { ambulante Beratungsstellen; } \\
\text { Fachkliniken; Krankenhäuser; } \\
\text { niedergelassene Therapeuten, } \\
\text { Ämter u. Behörden; sozial- } \\
\text { psychiatrischer Dienst }\end{array}$ & $\begin{array}{l}\text { Kinderkrankenhaus Hamburg- } \\
\text { Altona (Abt. Kinderorthopädie) }\end{array}$ & $\begin{array}{l}\text { ambulante Beratungsstellen; Fach- } \\
\text { kliniken; Krankenhäuser; nieder- } \\
\text { gelassene Therapeuten }\end{array}$ & Fachkliniken, Krankenhäuser \\
\hline Finanzierung & $\begin{array}{l}\text { Eigenmittel; Mitgliedsbeiträge; } \\
\text { Krankenkassen; private Spenden; } \\
\text { Sponsoren }\end{array}$ & $\begin{array}{l}\text { Mitgliedsbeiträge; Krankenkassen; } \\
\text { private Spenden; Kursgebühren }\end{array}$ & Mitgliedsbeiträge; private Spenden & Mitgliedsbeiträge \\
\hline
\end{tabular}

allg. Info: allgemeine Informationen; begr.: begrenzt; div.: diverse; Fort: Fortbildung; k.A.: keine (näheren) Angaben; Kur: Kurse; Med: Medien; öffentl.: öffentlich; Öff: Öffentlichkeitsarbeit; Sem: Seminare; SH: Selbsthilfe; SHG: Selbsthilfegruppe(n); SHO: Selbsthilfeorganisation(en); Tag: Tagungen; unbegr.: unbegrenzt; Ver: Veranstaltungen; Vor: Vorträge; B: Berlin; F: Frankfurt; HF: Herford; HH: Hamburg; K: Köln; KA: Karlsruhe; M: München; MA: Mannheim; N: Nürnberg; OS: Osnabrück; S: Stuttgart; SB: Saarbrücken. 
Tab. 13. Selbsthilfevereinigungen: Neurologische Erkrankungen / Behinderungen II

\begin{tabular}{|c|c|c|c|c|}
\hline Organisation & $\begin{array}{l}\text { Selbsthilfe Schlafapnoe } \\
\text { Wuppertal e.V. }\end{array}$ & $\begin{array}{l}\text { Deutsche Huntington-Hilfe e.V. } \\
\text { Geschäftsstelle «Soziale Dienste» }\end{array}$ & $\begin{array}{l}\text { Bundesarbeitsgemeinschaft zur } \\
\text { Förderung von Kindern und } \\
\text { Jugendlichen mit Teilleistungs- } \\
\text { störungen MCD / HKS (BAG-TL) } \\
\text { e.V. }\end{array}$ & $\begin{array}{l}\text { Deutsche Restless Legs } \\
\text { Vereinigung (RLS) e.V. }\end{array}$ \\
\hline Adresse & $\begin{array}{l}\text { Udo Bertram } \\
\text { Am Burgholz } 6 \\
\text { 42349 Wuppertal } \\
\text { Tel. 0202 40-8917, Fax -98 } 17 \\
\text { info@schlafapnoe-online.de } \\
\text { www.schlafapnoe-online.de } \\
\text { (Experten-Chat) }\end{array}$ & $\begin{array}{l}\text { Jürgen Pertek } \\
\text { Börsenstraße } 10 \\
\text { 47051 Duisburg } \\
\text { Tel. } 0203 \text { 229-15, Fax -25 } \\
\text { dhh@dhh-ev.de } \\
\text { www.dhh-ev.de }\end{array}$ & $\begin{array}{l}\text { Andreas Herzog } \\
\text { Wendelinstraße } 64 \\
50933 \text { Köln } \\
\text { Tel. 0221 49-959 98, Fax -114 } 64 \\
\text { BAG-Eichler@t-online.de }\end{array}$ & $\begin{array}{l}\text { - Geschäftsstelle - } \\
\text { Sabine Miesch, Monika Wenig, } \\
\text { Jürgen Schmidt-Evers } \\
\text { Schillerstraße } 3 \text { a } \\
\text { 80336 München } \\
\text { Tel. } 0895502 \text { 88-80, Fax -81 } \\
\text { RLS-eV@t-online.de } \\
\text { www.restless-legs.org (Forum) }\end{array}$ \\
\hline Kontaktaufnahme & $\begin{array}{l}\text { telefonisch Do 20:00-21:00 Uhr } \\
\text { (Hotline 0202 408 7645) }\end{array}$ & $\begin{array}{l}\text { persönlich u. telefonisch Mo-Fr } \\
\text { 8:30-15:00 Uhr; persönliche } \\
\text { Beratung nach Terminabsprache }\end{array}$ & $\begin{array}{l}\text { persönlich u. telefonisch Mo-Fr } \\
\text { 9:00-16:30 Uhr }\end{array}$ & $\begin{array}{l}\text { telefonisch Mo-Do 10:00-15:00 } \\
\text { Uhr }\end{array}$ \\
\hline Zielgruppe & $\begin{array}{l}\text { Schnarcher; Apnoiker u. Men- } \\
\text { schen mit Schlafstörungen }\end{array}$ & $\begin{array}{l}\text { Menschen mit Chorea Huntington; } \\
\text { Risikopersonen; Angehörige u. } \\
\text { Fachkräfte }\end{array}$ & $\begin{array}{l}\text { Betroffene u. deren Eltern; } \\
\text { Therapeuten u. Ärzte }\end{array}$ & Betroffene \\
\hline Aufgaben & $\begin{array}{l}\text { Beratung; Aufklärung; Hilfe- } \\
\text { stellung; Unterstützung u. Öffent- } \\
\text { lichkeitsarbeit }\end{array}$ & Beratung u. Information & Beratung u. Information & \\
\hline Angebote & $\begin{array}{l}\text { allg. Info (Schlaflabor-Adressen, } \\
\text { Schlafapnoe-Shop); Beratung } \\
\text { durch Selbstbetroffene u. Fach- } \\
\text { leute; Interessenvertretung der } \\
\text { Betroffenen (Öff, Ver / Vor, Tag, } \\
\text { Med); SHG (offene Gruppe, Teil- } \\
\text { nahmedauer unbegr., Ziele: } \\
\text { gemeinsam nach Lösungen suchen, } \\
\text { Hilfe durch Hilfe; } \\
\text { ohne therapeutische Leitung) }\end{array}$ & $\begin{array}{l}\text { allg. Info; Beratung durch } \\
\text { Fachleute u. Laien; Interessen- } \\
\text { vertretung der Betroffenen (Öff, } \\
\text { Ver / Vor, Tag, Med); SHG }\end{array}$ & $\begin{array}{l}\text { allg. Info (Info-Paket); Beratung } \\
\text { durch Selbstbetroffene u. } \\
\text { Fachleute (Zusammenarbeit mit } \\
\text { dem Kölner Therapiezentrum); } \\
\text { Interessenvertretung der Betroffe- } \\
\text { nen (Öff, Ver / Vor, Sem / Kur, } \\
\text { Med: Zeitschrift «Rundblick»); } \\
\text { bundesweit SHG }\end{array}$ & $\begin{array}{l}\text { Beratung durch Selbstbetroffene u. } \\
\text { Fachleute; Interessenvertretung } \\
\text { der Betroffenen (Öff, Ver, Med: } \\
\text { Zeitung «Rastlos», RLS Medical } \\
\text { Bulletin, Ratgeber f. Betroffene); } \\
\text { bundesweit Regionalbeiräte der } \\
\text { RLS e.V. }\end{array}$ \\
\hline Leitung & Udo Bertram & $\begin{array}{l}\text { Georg Hirschler (1. Vorsitzender); } \\
\text { Christiane Lohkamp } \\
\text { (stellv. Vorsitzende) }\end{array}$ & Eckhard Barth (1. Vorsitzender) & $\begin{array}{l}\text { Sabine Miesch (1. Vorsitzende); } \\
\text { Monika Wenig (2. Vorsitzende); } \\
\text { Jürgen Schmidt-Evers } \\
\text { (3. Vorsitzender) }\end{array}$ \\
\hline Personal & k.A. & $\begin{array}{l}1 \text { Dipl.-Sozialwiss. } \\
\text { u. } 1 \text { Verwaltungskraft }\end{array}$ & Andreas Herzog & ehrenamtliche Helfer \\
\hline Zusammenarbeit & $\begin{array}{l}\text { Informationsaustausch mit } \\
\text { anderen SHG f. Schlafapnoe }\end{array}$ & Fachkliniken; Ämter u. Behörden & Fachkliniken (im Seminarbereich) & $\begin{array}{l}\text { Deutsche Parkinson Gesellschaft; } \\
\text { Schlaf Apnoiker; RLS Foundation } \\
\text { USA }\end{array}$ \\
\hline Finanzierung & $\begin{array}{l}\text { öffentl. Zuschüsse; Mitglieds- } \\
\text { beiträge; private Spenden }\end{array}$ & $\begin{array}{l}\text { öffentl. Zuschüsse; Mitglieds- } \\
\text { beiträge; Krankenkassen; private } \\
\text { Spenden }\end{array}$ & Mitgliedsbeiträge; private Spenden & $\begin{array}{l}\text { öffentl. Zuschüsse; Eigenmittel; } \\
\text { Mitgliedsbeiträge }\end{array}$ \\
\hline
\end{tabular}

allg. Info: allgemeine Informationen; begr.: begrenzt; div.: diverse; Fort: Fortbildung; k.A.: keine (näheren) Angaben; Kur: Kurse; Med: Medien; öffentl.: öffentlich; Öff: Öffentlichkeitsarbeit; Sem: Seminare; SH: Selbsthilfe; SHG: Selbsthilfegruppe(n); SHO: Selbsthilfeorganisation(en); Tag: Tagungen; unbegr.: unbegrenzt; Ver: Veranstaltungen; Vor: Vorträge. 
Tab. 14. Selbsthilfevereinigungen: Persönlichkeitsstörungen und psychische Probleme

\begin{tabular}{|c|c|c|}
\hline Organisation & Anonyme Borderliner Interessengemeinschaft (BA) e.V. & $\begin{array}{l}\text { Emotions Anonymous Interessengemeinschaft (EA) e.V. } \\
\text { Selbsthilfegruppe für emotionale Gesundheit }\end{array}$ \\
\hline Adresse & $\begin{array}{l}\text { Ida Maria } \\
\text { Postfach } 100140 \\
\text { 50441 Köln } \\
\text { Tel. } 0752228227\end{array}$ & $\begin{array}{l}\text { Katzbachstraße } 33 \\
10965 \text { Berlin } \\
\text { Tel. 030-786 7984, Fax -78896178 } \\
\text { info@EmotionsAnonymous.de } \\
\text { www.EmotionsAnonymous.de }\end{array}$ \\
\hline Kontaktaufnahme & telefonisch (bitte Ida Maria verlangen) u. schriftlich & telefonisch Do 14:00-17:00 Uhr \\
\hline Zielgruppe & $\begin{array}{l}\text { Menschen mit destruktivem Verhalten, Denken, Fühlen, mit früher } \\
\text { Störung (Borderline-Syndrom, Narzissmus u.ä.) }\end{array}$ & $\begin{array}{l}\text { Menschen mit emotionalen Störungen (Ängsten, Depressionen, } \\
\text { Neurosen, Sucht, Zwänge) }\end{array}$ \\
\hline Aufgaben & $\begin{array}{l}\text { Unterstützung der BA-Gruppen (Borderline Anonymous); Kontakt } \\
\text { zw. den einzelnen Gruppen halten u. fördern; Beantwortung der Post }\end{array}$ & k.A. \\
\hline Angebote & $\begin{array}{l}\text { allg. Info; SHG (offene Gruppe, Teilnahmedauer unbegr., Ziele: Aus- } \\
\text { tausch von Erfahrung, Kraft u. Hoffnung, ohne therapeutische Leitung, } \\
\text { Arbeit nach dem } 12 \text { Schritte-Programm der Anonymen Alkoholiker) }\end{array}$ & $\begin{array}{l}\text { Interessenvertretung der Betroffenen (Öff, Ver / Vor, Tag, Med); } \\
\text { bundesweit etwa } 300 \text { SHG f. Menschen mit emotionalen Störungen } \\
\text { (offene Gruppe, Teilnahmedauer unbegr., Ziele: Hilfe bei emotionalen } \\
\text { Störungen, Erleichterung der Beschwerden, Steigerung des Selbst- } \\
\text { vertrauens; ohne therapeutische Leitung, Arbeit nach dem } 12 \text { Schritte- } \\
\text { Programm der Anonymen Alkoholiker) }\end{array}$ \\
\hline Leitung & Vorstand u. Geschäftsführung & Vorstand \\
\hline Personal & ausschließlich selbstbetroffene, ehrenamtliche Mitarbeiter & 1 Sachbearbeiterin; Aushilfskräfte; ehrenamtliche Mitarbeiter \\
\hline Zusammenarbeit & Anonyme SHG (insbesondere Anonyme Alkoholiker) & $\begin{array}{l}\text { Anonyme SHG (v.a. Anonyme Alkoholiker); ambulante Beratungs- } \\
\text { stellen; niedergelassene Therapeuten; Fachkliniken; Krankenhäuser; } \\
\text { Ämter u. Behörden; sozialpsychiatrischer Dienst }\end{array}$ \\
\hline Finanzierung & Eigenmittel & private Spenden; Verkauf von Literatur \\
\hline
\end{tabular}

allg. Info: allgemeine Informationen; begr.: begrenzt; div.: diverse; Fort: Fortbildung; k.A.: keine (näheren) Angaben; Kur: Kurse; Med: Medien; öffentl.: öffentlich; Öff: Öffentlichkeitsarbeit; Sem: Seminare; SH: Selbsthilfe; SHG: Selbsthilfegruppe(n); SHO: Selbsthilfeorganisation(en); Tag: Tagungen; unbegr.: unbegrenzt; Ver: Veranstaltungen; Vor: Vorträge. 
Tab. 15a. Selbsthilfevereinigungen: Sucht / Abhängigkeit I

\begin{tabular}{|c|c|c|c|c|}
\hline Organisation & $\begin{array}{l}\text { Deutscher Guttempler Orden } \\
\text { (I.O.G.T.) e.V. }\end{array}$ & $\begin{array}{l}\text { Freundeskreise für Suchtkranken- } \\
\text { hilfe Bundesverband e.V. }\end{array}$ & Al-Anon-Familiengruppen & $\begin{array}{l}\text { KREUZBUND e.V. Selbsthilfe- } \\
\text { und Helfergemeinschaft für Sucht- } \\
\text { kranke und deren Angehörige }\end{array}$ \\
\hline Adresse & $\begin{array}{l}\text { Wiebke Schneider } \\
\text { Adenauerallee } 45 \\
20097 \text { Hamburg } \\
\text { Tel.040 24-5880, Fax -1430 } \\
\text { guttempler@t-online.de } \\
\text { www.guttempler.de }\end{array}$ & $\begin{array}{l}\text { Kurt-Schumacher-Straße } 2 \\
34117 \text { Kassel } \\
\text { Tel. 0561-7804 13, Fax -7112 } 82 \\
\text { mail@freundeskreise-sucht.de } \\
\text { www.freundeskreise-sucht.de }\end{array}$ & $\begin{array}{l}\text { - Zentrales Dienstbüro - } \\
\text { Brigitte Schons } \\
\text { Emilienstraße } 4 \\
\text { 45128 Essen } \\
\text { Tel.0201-7730-07, Fax -08 } \\
\text { al-anon.zdb@t-online.de } \\
\text { www.al-anon.de (On-line Meetings) }\end{array}$ & $\begin{array}{l}\text { - Bundesgeschäftsstelle - } \\
\text { Judith Hüsken } \\
\text { Postfach } 1867 \\
\text { 59008 Hamm } \\
\text { Münsterstraße } 25 \\
\text { 59065 Hamm } \\
\text { Tel. 02381-6727 2-0, Fax -33 } \\
\text { info@kreuzbund.de } \\
\text { www.kreuzbund.de }\end{array}$ \\
\hline Kontaktaufnahme & persönlich u. telefonisch & telefonisch & $\begin{array}{l}\text { telefonisch Mo u. Mi 9:00-19:00, } \\
\text { Di u. Do 9:00-17:00; Fr 9:00-15:00 } \\
\text { Uhr }\end{array}$ & $\begin{array}{l}\text { telefonisch Mo-Do 8:00-16:00 u. } \\
\text { Fr 8:00-12:00 Uhr; persönlich nach } \\
\text { Vereinbarung }\end{array}$ \\
\hline Zielgruppe & $\begin{array}{l}\text { Menschen mit Suchtproblemen u. } \\
\text { deren Angehörige }\end{array}$ & $\begin{array}{l}\text { Alkohol- u. Medikamenten- } \\
\text { abhängige }\end{array}$ & $\begin{array}{l}\text { Angehörige u. Freunde von } \\
\text { Alkoholikern }\end{array}$ & $\begin{array}{l}\text { Alkohol- und Medikamenten- } \\
\text { abhängige sowie deren Angehörige }\end{array}$ \\
\hline Aufgaben & $\begin{array}{l}\text { Hilfe zur SH für Menschen mit } \\
\text { Suchtproblemen u. deren } \\
\text { Angehörige }\end{array}$ & $\begin{array}{l}\text { Vertretung der Interessen der } \\
\text { Freundeskreise auf Bundesebene; } \\
\text { Information u. Öffentlichkeits- } \\
\text { arbeit; Förderung des Erfahrungs- } \\
\text { austausches unter den Freundes- } \\
\text { kreisen; Zusammenarbeit u. } \\
\text { Erfahrungsaustausch mit anderen } \\
\text { Selbsthilfe- u. Abstinenzverbän- } \\
\text { den; Durchführung von Fortbil- } \\
\text { dungsseminaren f. Gruppenleiter } \\
\text { in den Freundeskreisen; Arbeits- } \\
\text { kreise }\end{array}$ & $\begin{array}{l}\text { Hilfe f. Angehörige u. Freunde von } \\
\text { Alkoholikern }\end{array}$ & $\begin{array}{l}\text { SH für Suchtkranke u. deren } \\
\text { Angehörige (insbesondere Nach- } \\
\text { sorge) }\end{array}$ \\
\hline Angebote & $\begin{array}{l}\text { Beratung durch Selbstbetroffene; } \\
\text { Interessenvertretung der Betroffe- } \\
\text { nen (Öff, Ver / Vor, Tag, Sem / } \\
\text { Kur, Fort, Med: Zeitschrift } \\
\text { «Guttempler», div. Publikationen); } \\
\text { bundesweit SHG f. Suchtgefähr- } \\
\text { dete, Abhängige u. Angehörige } \\
\text { (offene Gruppe, Teilnahmedauer } \\
\text { unbegr., Ziele: Hilfe zur SH, Nach- } \\
\text { sorge); bundesweit etwa 500 SHG }\end{array}$ & $\begin{array}{l}\text { allg. Info; Interessenvertretung der } \\
\text { Betroffenen (Öff, Ver / Vor, Tag, } \\
\text { Sem / Kur, Fort: f. Gruppenleiter, } \\
\text { Med: Informationsmaterialien, } \\
\text { Broschüren, Zeitschrift «Freundes- } \\
\text { kreis-Journal»); bundesweit etwa } \\
860 \text { Freundeskreis-Gruppen }\end{array}$ & $\begin{array}{l}\text { Beratung durch Selbstbetroffene; } \\
\text { bundesweit SHG (offene Gruppe, } \\
\text { Teilnahmedauer unbegr., ohne } \\
\text { therapeutische Leitung) }\end{array}$ & $\begin{array}{l}\text { allg. Info; Beratung durch Selbst- } \\
\text { betroffene und Laien; Interessen- } \\
\text { vertretung der Betroffenen (Öff, } \\
\text { Ver / Vor, Tag, Sem / Kur, Fort, } \\
\text { Med: Faltblätter zu den einzelnen } \\
\text { Bereichen der Kreuzbundarbeit, } \\
\text { Zeitschrift «Weggefährte»); } \\
\text { bundesweit SHG f. Abhängige u. } \\
\text { Angehörige (offene Gruppe, } \\
\text { Teilnahmedauer unbegr., Ziele: } \\
\text { Hilfe zur SH, ohne therapeutische } \\
\text { Leitung) }\end{array}$ \\
\hline Leitung & k.A. & $\begin{array}{l}\text { Bundesvorstand (ehrenamtlich / } \\
\text { unentgeltlich) }\end{array}$ & k.A. & Vorstand \\
\hline Personal & ehrenamtliche Helfer & $\begin{array}{l}\text { zwei hauptamtliche Mitarbeiterin- } \\
\text { nen }\end{array}$ & k.A. & k.A. \\
\hline Zusammenarbeit & $\begin{array}{l}\text { Abstinenz- u. Selbsthilfeverbände; } \\
\text { Deutsche Hauptstelle gegen die } \\
\text { Suchtgefahren u. Landesstellen; } \\
\text { Paritätischer Bundesverband u. } \\
\text { Landesverbände }\end{array}$ & $\begin{array}{l}\text { Gesamtverband f. Suchtkranken- } \\
\text { hilfe im Diakonischen Werk der } \\
\text { EKD e.V.; Deutsche Hauptstelle } \\
\text { gegen Suchtgefahren }\end{array}$ & $\begin{array}{l}\text { nur mit Einrichtungen, die im } \\
\text { Einklang mit den Traditionen der } \\
\text { AA stehen }\end{array}$ & k.A. \\
\hline Finanzierung & Mitgliedsbeiträge & $\begin{array}{l}\text { Zuwendungen der Bundesversi- } \\
\text { cherungsanstalt f. Angestellte } \\
\text { (BfA); Projektmittel des Bundes- } \\
\text { ministeriums f. Gesundheit } \\
\text { (BMG); Bundesverbände von } \\
\text { Krankenkassen }\end{array}$ & Eigenmittel & k.A. \\
\hline
\end{tabular}

allg. Info: allgemeine Informationen; begr.: begrenzt; div.: diverse; Fort: Fortbildung; k.A.: keine (näheren) Angaben; Kur: Kurse; Med: Medien; öffentl.: öffentlich; Öff: Öffentlichkeitsarbeit; Sem: Seminare; SH: Selbsthilfe; SHG: Selbsthilfegruppe(n); SHO: Selbsthilfeorganisation(en); Tag: Tagungen; unbegr.: unbegrenzt; Ver: Veranstaltungen; Vor: Vorträge. 
Tab. 15b. Selbsthilfevereinigungen: Sucht / Abhängigkeit II

\begin{tabular}{|c|c|c|c|c|}
\hline Organisation & $\begin{array}{l}\text { LAGAYA e.V. } \\
\text { Frauen-Sucht-Beratungsstelle }\end{array}$ & $\begin{array}{l}\text { Anonyme Alkoholiker Interessen- } \\
\text { gemeinschaft e.V. }\end{array}$ & $\begin{array}{l}\text { Anonyme Ärzte Selbsthilfegruppe } \\
\text { Deutschland (AÄD) Spezialgrup- } \\
\text { pe der Anonymen Alkoholiker } \\
\text { (AA) }\end{array}$ & STIFTUNG SYNANON \\
\hline Adresse & $\begin{array}{l}\text { Hohenstaufenstraße } 17 \text { b } \\
70178 \text { Stuttgart } \\
\text { Tel. } 07116405490 \text { o. } 6403027 \text {, } \\
\text { Fax } 6076860\end{array}$ & $\begin{array}{l}\text { Herr Habedank } \\
\text { Lotte Branz Straße } 14 \\
\text { 80939 München } \\
\text { Tel. } 089 \text { 316-9500, Fax -5100 } \\
\text { gnenther@anonyme- } \\
\text { alkoholiker.de } \\
\text { www.anonyme-alkoholiker.de } \\
\text { (On-line Meetings) }\end{array}$ & $\begin{array}{l}\text { Dr. med. Maria-Theresia Conradty } \\
\text { Bahnhofstraße } 36 \\
86971 \text { Peiting } \\
\text { Tel. 08861-6115, Fax -6932 } 41 \\
\text { conradty@t-online.de }\end{array}$ & $\begin{array}{l}\text { Bernburger Straße } 10 \\
10963 \text { Berlin } \\
\text { Tel.030-5500-00, Fax -0220 } \\
\text { stiftung@synanon.de } \\
\text { www.synanon.de }\end{array}$ \\
\hline Kontaktaufnahme & $\begin{array}{l}\text { persönlich 17:00-19:00 Uhr } \\
\text { (Sprechstunde); telefonisch } \\
\text { Di u. Do 11:00-13:00 u. 15:00- } \\
\text { 17:00, Mi 11:00-19:00 u. Fr 11:00- } \\
\text { 13:00 Uhr }\end{array}$ & persönlich o. telefonisch & $\begin{array}{l}\text { persönlich Mo-Fr 8:00-9:00 Uhr; } \\
\text { telefonisch rund um die Uhr } \\
\text { (Anrufbeantworter, Rückruf bei } \\
\text { Angabe der Tel.-Nr. u. Grund des } \\
\text { Anrufes) }\end{array}$ & $\begin{array}{l}\text { persönliche } u \text {. telefonische } \\
\text { Beratung sowie Information } 24 \mathrm{~h} \\
\text { am Tag }\end{array}$ \\
\hline Zielgruppe & $\begin{array}{l}\text { drogen-, medikamenten- u. } \\
\text { alkoholabhängige Frauen; Frauen } \\
\text { mit Ess- u. Kaufsucht }\end{array}$ & Menschen mit Alkoholproblemen & $\begin{array}{l}\text { Ärzte mit Alkohol- u. Medikamen- } \\
\text { tenabhängigkeit }\end{array}$ & $\begin{array}{l}\text { Drogen-, Alkohol u. andere Sucht- } \\
\text { mittelabhängige; Mütter u. Väter } \\
\text { mit ihren Kindern }\end{array}$ \\
\hline Aufgaben & $\begin{array}{l}\text { Beratung u. psychosoziale } \\
\text { Betreuung; ambulante REHA; } \\
\text { Öffentlichkeitsarbeit }\end{array}$ & k.A. & $\begin{array}{l}\text { Kontaktaufnahme bei beruflichen } \\
\text { Schwierigkeiten in Verbindung mit } \\
\text { Alkoholproblemen; Information } \\
\text { über die Krankheit mit Identifika- } \\
\text { tion als Arzt }\end{array}$ & Hilfe bei Suchterkrankungen \\
\hline Angebote & $\begin{array}{l}\text { allg. Info; Beratung durch Fach- } \\
\text { leute; Interessenvertretung der } \\
\text { Betroffenen (Öff, Ver / Vor, Tag, } \\
\text { Sem / Kur, Fort, Med); SHG f. } \\
\text { trockene Alkoholikerinnen (offene } \\
\text { Gruppe, Teilnahmedauer unbegr., } \\
\text { Ziele: Erhaltung der Abstinenz, } \\
\text { soziale Kontakte aufbauen, Erler- } \\
\text { nen eines bewussten Umgangs mit } \\
\text { der Suchtproblematik, minimale } \\
\text { therapeutische Leitung); SHG f. } \\
\text { Frauen mit Essproblemen (offene } \\
\text { Gruppe, Teilnahmedauer unbegr., } \\
\text { Ziele: s.o., minimale therapeuti- } \\
\text { sche Leitung) }\end{array}$ & $\begin{array}{l}\text { Erfahrungsaustausch durch Selbst- } \\
\text { betroffene; Interessenvertretung } \\
\text { der Betroffenen (Öff, Ver) }\end{array}$ & $\begin{array}{l}\text { Beratung durch Selbstbetroffene u. } \\
\text { Fachleute; bundesweit SHG f. } \\
\text { selbstbetroffene Ärzte (offene } \\
\text { Gruppe, Teilnahmedauer unbegr., } \\
\text { Ziele: Abstinenz v. Alkohol u. } \\
\text { Medikamenten mit Suchtpotential, } \\
\text { bessere Lebens- u. berufliche } \\
\text { Qualität; ohne therapeutische } \\
\text { Leitung; 6-12 Teilnehmer) }\end{array}$ & $\begin{array}{l}\text { allg. Info; Beratung durch Betrof- } \\
\text { fene; Interessenvertretung der } \\
\text { Betroffenen (Öff, Ver / Vor, Tag, } \\
\text { Sem / Kur, Fort, Med); SHG f. } \\
\text { Süchtige (offene Gruppe, } \\
\text { Teilnahmedauer unbegr., Ziele: } \\
\text { drogenfreies Leben erlernen, ohne } \\
\text { therapeutische Leitung) }\end{array}$ \\
\hline Leitung & $\begin{array}{l}\text { Ulrike Ohnmeiß } \\
\text { (Geschäftsführerin) }\end{array}$ & k.A. & k.A. & Peter Elsing (Vorsitzender) \\
\hline Personal & $\begin{array}{l}1 \text { Dipl.-Psych.; } 1 \text { Dipl.-Päd.; } \\
2 \text { Dipl.-Soz.-Arb. }\end{array}$ & ehrenamtliche Helfer & k.A. & $\begin{array}{l}\text { alle Aufgaben werden von Betrof- } \\
\text { fenen erledigt }\end{array}$ \\
\hline Zusammenarbeit & $\begin{array}{l}\text { ambulante Beratungsstellen; Fach- } \\
\text { kliniken; Ämter u. Behörden }\end{array}$ & k.A. & $\begin{array}{l}\text { Anonyme Alkoholiker (AA) } \\
\text { Interessengemeinschaft e.V.; } \\
\text { Fachkliniken, Krankenhäuser, } \\
\text { niedergelassene Therapeuten) }\end{array}$ & \\
\hline Finanzierung & $\begin{array}{l}\text { öffentl. Zuschüsse; Eigenmittel; } \\
\text { Mitgliedsbeiträge; Krankenkassen; } \\
\text { private Spenden; Kursgebühren }\end{array}$ & Mitgliedsbeiträge & Eigenmittel, Mitgliedsbeiträge & $\begin{array}{l}\text { öffentl. Zuschüsse; Eigenmittel; } \\
\text { private Spenden }\end{array}$ \\
\hline
\end{tabular}

allg. Info: allgemeine Informationen; begr.: begrenzt; div.: diverse; Fort: Fortbildung; k.A.: keine (näheren) Angaben; Kur: Kurse; Med: Medien; öffentl.: öffentlich; Öff: Öffentlichkeitsarbeit; Sem: Seminare; SH: Selbsthilfe; SHG: Selbsthilfegruppe(n); SHO: Selbsthilfeorganisation(en); Tag: Tagungen; unbegr.: unbegrenzt; Ver: Veranstaltungen; Vor: Vorträge. 
Tab. 15c. Selbsthilfevereinigungen: Sucht / Abhängigkeit III

\begin{tabular}{|c|c|c|c|}
\hline Organisation & Anonyme Sexaholiker e.V. & $\begin{array}{l}\text { GA Anonyme Spieler Interessengemein- } \\
\text { schaft e.V. }\end{array}$ & Fachverband Glücksspielsucht e.V \\
\hline Adresse & $\begin{array}{l}\text { Postfach } 1262 \\
76002 \text { Karlsruhe } \\
\text { deutsch@sa.org } \\
\text { www.sa.org/a030uebersicht.html }\end{array}$ & $\begin{array}{l}\text { Eilbeker Weg } 20 \\
\text { 22089 Hamburg } \\
\text { Tel. } 0402099009\end{array}$ & $\begin{array}{l}\text { Auf der Freiheit } 25 \\
32052 \text { Herford } \\
\text { Tel. } 05221 \text { 5998-50, Fax -75 } \\
\text { spielsucht@t-online.de } \\
\text { www.gluecksspielsucht.de (Forum) }\end{array}$ \\
\hline Kontaktaufnahme & nur schriftlich & telefonisch Mo-Fr 9:00-21:00 Uhr & k.A. \\
\hline Zielgruppe & Sexsüchtige & Spieler (Glücksspiel um Geld) & glücksspielsüchtige Menschen \\
\hline Aufgaben & $\begin{array}{l}\text { SHG nach den } 12 \text { Traditionen der Anonymen } \\
\text { Sexaholiker }\end{array}$ & $\begin{array}{l}\text { SH f. Spieler analog den } 12 \text {-Schritte } \\
\text { Gruppen der Anonymen Alkoholiker, } \\
\text { Emotions Anonymous usw. }\end{array}$ & $\begin{array}{l}\text { Archiv u. Informationsstelle; Kontakt- } \\
\text { forum f. Praktiker u. Wissenschaftler; Fort } \\
\text { u. Weiterbildungsangebote f. Berufsgrup- } \\
\text { pen, die mit diesem Problem konfrontiert } \\
\text { werden; Zusammenarbeit mit Institutio- } \\
\text { nen ähnlicher Zielsetzung; Anregung von } \\
\text { Forschungsvorhaben; Information der } \\
\text { Öffentlichkeit; Interessenvertretung }\end{array}$ \\
\hline Angebote & bundesweit SHG & $\begin{array}{l}\text { Beratung durch Selbstbetroffene; } \\
\text { bundesweit etwa } 100 \text { GA-SHG (offene } \\
\text { Gruppe, Teilnahmedauer unbegr., Ziele: } \\
\text { gegenseitige Hilfe) }\end{array}$ & k.A. \\
\hline Leitung & k.A. & k.A. & $\begin{array}{l}\text { Ilona Füchtenschneider (Vorsitzende); } \\
\text { Martina Allstedt u. Horst Witt } \\
\text { (Stellvertreter) }\end{array}$ \\
\hline Personal & k.A. & k.A. & k.A. \\
\hline Zusammenarbeit & k.A. & andere SHG & k.A. \\
\hline Finanzierung & k.A & private Spenden & k.A. \\
\hline
\end{tabular}

allg. Info: allgemeine Informationen; begr.: begrenzt; div.: diverse; Fort: Fortbildung; k.A.: keine (näheren) Angaben; Kur: Kurse; Med: Medien; öffentl.: öffentlich; Öff: Öffentlichkeitsarbeit; Sem: Seminare; SH: Selbsthilfe; SHG: Selbsthilfegruppe(n); SHO: Selbsthilfeorganisation(en); Tag: Tagungen; unbegr.: unbegrenzt; Ver: Veranstaltungen; Vor: Vorträge.

Tab. 16. Selbsthilfevereinigungen: Zwangsstörungen

\begin{tabular}{|c|c|c|}
\hline Organisation & Infostelle Trichotillomanie & Deutsche Gesellschaft für Zwangserkrankungen (DGZ) e.V. \\
\hline \multirow[t]{6}{*}{ Adresse } & Antonia Peters & Burkhard Ciupka, Susanne Felske, Teresa Czubec \\
\hline & Papenstraße 63 b & Postfach 1545 \\
\hline & 22089 Hamburg & 49005 Osnabrück \\
\hline & Tel. 0402006139 & Tel. 0541357 44-33, Fax -35 \\
\hline & TrichoHH@t-online.de & dgz.@luce.psycho.uni-osnabrueck.de \\
\hline & www.trichotillomanie.purespace.de (Forum) & www.zwaenge.de \\
\hline Kontaktaufnahme & telefonisch Mo-Do 9:00-12:00 u. 15:00-22:00; So 19:30-22:00 Uhr & $\begin{array}{l}\text { persönlich nach Vereinbarung; telefonisch Mo-Do 10:00-12:00 u. } \\
\text { 14:00-16:30; Fr 10:00-14:00 Uhr }\end{array}$ \\
\hline Zielgruppe & $\begin{array}{l}\text { Betroffene u. deren Angehörige; Ärzte u. Therapeuten; } \\
\text { alle Interessierten }\end{array}$ & Betroffene u. deren Angehörige; Therapeuten \\
\hline Aufgaben & Information u. Aufklärung; Gründung von SHG & Information; Beratung; Öffentlichkeitsarbeit; Forschung \\
\hline Angebote & $\begin{array}{l}\text { allg. Info; Beratung durch Selbstbetroffene u. Fachleute; Interessenver- } \\
\text { tretung der Betroffenen (Öff, Ver / Vor: regionale Infoveranstaltungen, } \\
\text { Med); SHG in F, HH u. L (offene Gruppe, Teilnahmedauer unbegr., } \\
\text { ohne therapeutische Leitung) }\end{array}$ & $\begin{array}{l}\text { allg. Info; Beratung durch Selbstbetroffene, Fachleute u. Laien; } \\
\text { Interessenvertretung der Betroffenen (Öff, Ver / Vor, Tag, Med: } \\
\text { Zeitschrift «Zaktuell»); bundesweit SHG }\end{array}$ \\
\hline Leitung & Antonia Peters & Prof. Dr. A. Rothenberger (1. Vorsitzender) \\
\hline Personal & Antonia Peters & 2 Kauffrauen f. Bürokommunikation \\
\hline Zusammenarbeit & $\begin{array}{l}\text { Deutsche Gesellschaft für Zwangserkrankungen (DGZ) e.V.; Kontakt } \\
\text { und Informationsstelle KISS in Hamburg }\end{array}$ & Krankenhäuser; Fachkliniken; niedergelassene Therapeuten \\
\hline Finanzierung & öffentl. Zuschüsse & Mitgliedsbeiträge; private Spenden \\
\hline
\end{tabular}

allg. Info: allgemeine Informationen; begr.: begrenzt; div.: diverse; Fort: Fortbildung; k.A.: keine (näheren) Angaben; Kur: Kurse; Med: Medien; öffentl.: öffentlich; Öff: Öffentlichkeitsarbeit; Sem: Seminare; SH: Selbsthilfe; SHG: Selbsthilfegruppe(n); SHO: Selbsthilfeorganisation(en); Tag: Tagungen; unbegr.: unbegrenzt; Ver: Veranstaltungen; Vor: Vorträge. 